\title{
Incendiarismo y Pirocultura en el Bosque Tropical Seco de Costa Rica. La Historia del Fuego como Historia Aplicada
}

Wilson Picado Umaña ${ }^{1}$, Carlos Cruz Chaves ${ }^{2}$

\section{RESUMEN}

Este artículo analiza la evolución de los incendios forestales en Costa Rica desde la perspectiva de la Historia Aplicada. Su objetivo es relacionar el desarrollo de los incendios forestales con los cambios ocurridos en la estructura agraria del país en los últimos años. Para ello aprovecha el marco teórico de la Ecología del Fuego y de la Historia del Fuego para identificar los procesos sociales e históricos que afectan la conformación del régimen de incendios. El estudio se fundamenta en la revisión de fuentes primarias y secundarias, así como de mapas y estadísticas públicas.

Palabras clave: Historia del Fuego; Incendios Forestales; Bosque Tropical Seco; Historia Aplicada; Costa Rica.

\footnotetext{
1 Doctor en Historia (Universidad de Santiago de Compostela, España). Profesor de la Escuela de Historia y coordinador del Observatorio de Historia Agroecológica y Ambiental, de la Universidad Nacional, Costa Rica. ORCID: https://orcid.org/0000-0003-3882-1843. E-mail: wpicado@gmail.com

2 Egresado de la Maestría en Historia Aplicada (Universidad Nacional, Costa Rica). Profesor de la Sede Regional Chorotega e investigador del Observatorio de Historia Agroecológica y Ambiental de esa misma universidad. E-mail: carlos.cruz.chaves@una.cr
} 
"We are fire creatures from an ice age", Stephen J. Pyne

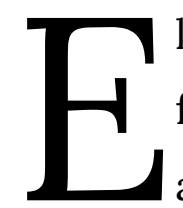
1 año de 1998 fue histórico para Costa Rica en términos de incendios forestales. En dicho año ocurrieron cerca de mil quinientos eventos, afectando unas 60 mil hectáreas en todo el territorio nacional. Bosques, tierras de cultivo, grandes pastizales y terrenos en barbecho fueron quemados en un año que ha sido uno de los más críticos en Costa Rica en las últimas dos décadas. Como era de esperar, la prensa de la época le brindó una amplia cobertura al problema. El periódico La República del 28 de marzo daba cuenta de la situación con un título explícito, "Arde Guanacaste", haciendo referencia a la provincia situada en el noroeste de Costa Rica ${ }^{3}$. El "depredador ardiente", como literariamente lo llamó un periodista, estuvo en las salas de redacción de los principales periódicos del país desde el mes de enero, cuando empezaron a contabilizarse los incendios en el Pacífico de Costa Rica.

La preocupación era, además, regional. Otro foco de interés de las noticias fueron los incendios que ocurrían, casi simultáneamente, en Brasil, México y Centroamérica. En marzo de ese año, el periódico La Nación informaba sobre un incendio que "devoraba" el estado amazónico de Roraima, en el límite con Guyana y Venezuela ${ }^{4}$. Dos días después, en el mismo periódico se retomaba el caso, esta vez precisando que la cobertura del incendio era de 40 mil kilómetros cuadrados, con unos 2 mil focos de propagación ${ }^{5}$. En mayo la atención se volcó sobre México, con más de 10 mil incendios y donde el humo generado por las quemas afectaba a la población, a la vez que el agua escaseaba. Era, según el redactor de la nota, "el peor drama ecológico de México en los últimos 70 años", particularmente para los habitantes de Ciudad de México ${ }^{6}$.

\footnotetext{
${ }^{3}$ Rocío Estrada Alvarado, "Arde Guanacaste", La República (Costa Rica), 1998, 5A.

4 "Fuego devora Amazonas", La Nación (Costa Rica), 20 de marzo de 1998, 18A.

5 "Brasil impotente ante el fuego", La Nación (Costa Rica), 22 de marzo de 1998, 19A.

6 "México está que arde", La Nación (Costa Rica), 21 de mayo de 1998, 21A.
} 
Una nota del 20 de mayo señalaba que Centroamérica se encontraba sofocada por el humo y la bruma, originados por los incendios forestales ${ }^{7}$. En Guatemala se contabilizaban más de 65 mil hectáreas cubiertas por el fuego, mientras que el número de incendios en El Salvador superaba el millar, motivando una declaratoria de alerta roja por parte de las autoridades. En Nicaragua, el gobierno se declaró "indefenso" para controlar el fuego en el Caribe, el centro y el Pacífico del país. La concentración de humo fue tal en la región que causó problemas respiratorios entre la población y alteró el tráfico aéreo en los principales aeropuertos, como el Aurora de Guatemala, el Toncontín de Honduras y el Sandino de Managua ${ }^{8}$.

Aunque en ese momento no fue advertido, 1998 fue un año dramático no solo para Costa Rica y la región centroamericana, Brasil o México, sino también para el planeta entero. Empezando desde 1997, dicho año formó parte de una crítica coyuntura global en lo que respecta a los incendios forestales; una en la cual "el mundo se incendió", como lo indicaban los encargados de un informe del Fondo Mundial para la Naturaleza y la $\mathrm{IUCN}^{9}$. En efecto, algunos cálculos estimaron que durante ese período se quemaron más de 20 millones de hectáreas en todo el mundo, siendo el Sudeste de Asia la región más afectada. Según el informe, en el sudeste asiático ardieron entre 8 y 10 millones de hectáreas, de las cuales al menos la mitad estaban cubiertas por bosques ${ }^{10}$. Las pérdidas económicas se contaron en unos 10 billones de dólares, mientras que la población afectada por el humo fue de unos 70 millones. En el Amazonas se quemaron unos tres millones de hectáreas, dos millones en Rusia, cerca de 5 millones en Norteamérica y un cuarto de millón de hectáreas en el sur de Europa. El fuego predominó en casi todas las biotas del mundo en un año que, vale recordar, fue uno de los más cálidos en el planeta desde que se tienen registros confiables de temperaturas ${ }^{11}$.

\footnotetext{
${ }^{7}$ Rubén Pasos et al, Incendios forestales y agrícolas en Centroamérica. Balance de 1998 (El Salvador: Comisión Centroamericana de Ambiente y Desarrollo-Consejo Centroamericano de Bosques y Áreas Protegidas, 1998).

8 "Humo asfixia al istmo", La Nación (Costa Rica), 20 de mayo de 1998, 18A.

${ }_{9}^{9}$ Andy Rowell; Peter Moore, Global Review of Forest Fires (Suiza: WWF-IUCN, 1999).

10 Stephen J. Pyne, Fire. A Brief History (University of Washington Press, 2001), 172.

11 Organización Meteorológica Mundial, Declaración de la OMM sobre el estado del clima mundial en 2015 (Suiza, 2016).
} 


\section{LA NARRATIVA DEL FUEGO}

Las temporadas de 1997 y 1998 marcaron una ruptura en la forma como se comprendía y se gestionaba el fuego. En medio de una atención cada vez más mediática, los expertos de diferentes países llegaron al acuerdo de que estaban ocurriendo una serie de cambios en los regímenes de incendios del planeta que, si no eran bien entendidos, podían afectar la capacidad de gestión del fuego ${ }^{12}$. Antes que nada, parecía claro que las políticas de supresión de incendios eran ineficaces y que su aplicación podía tener incluso consecuencias no deseadas sobre la salud de los ecosistemas. Asimismo, que la dinámica de los eventos ya no era solo de tipo local o regional, sino que se insertaba en una escala global, asociada a procesos como el calentamiento global y la influencia de fenómenos como El Niño-Oscilación del Sur (ENOS).

La coyuntura obligó a crear, o a fortalecer según fuera el caso, la organización regional y global para la atención de los incendios forestales. Así, por ejemplo, en Centroamérica, apenas un par de meses después de la trágica temporada de 1998, los gobiernos nacionales acordaron convenios de cooperación y coordinación en una reunión celebrada en San Pedro de Sula, en junio de ese año ${ }^{13}$. En Costa Rica, si bien ya existían experiencias y programas desde la década de 1980, fue a partir de 1997 cuando se institucionalizó la gestión mediante la creación de la Comisión Nacional de Incendios, con la participación de funcionarios provenientes de las Áreas de Conservación, el Cuerpo de Bomberos, el Ministerio de Agricultura y Ganadería, entre $\operatorname{otros}^{14}$.

No obstante lo anterior, debe decirse que el surgimiento de instituciones y de programas no ha avanzado, como se esperaba, al mismo ritmo que la creación de una cultura de conocimiento y debate entre la población acerca de los incendios forestales. Si se toma como ejemplo la cobertura que realiza la prensa en Costa Rica, el fuego continúa siendo el "enemigo" por combatir y eliminar. En el contexto de una

\footnotetext{
12 Rowell; Moore, Global Review, p. 20. Y: Ludwig Schindler et al., Incendios Forestales en Guatemala, Honduras y Nicaragua. Análisis de la situación presente y acciones a seguir (Alemania: Agencia Alemana de Cooperación Técnica, 2002).

${ }^{13}$ Comisión Centroamericana de Ambiente y Desarrollo, Actas de la reunión Problemas y perspectivas en

materia de incendios en América Central (Honduras, 1998). Y: Programa de Desarrollo Sostenible en Zonas de Frontera Agrícola de

Centroamérica, Atlas Centroamericano de Incendios (Panamá, 1998).

14 Decreto Ejecutivo N. 26399-MINAE, publicado en La Gaceta N. 206, de 27 de octubre de 1997.
} 
percepción social de los parques nacionales y de las áreas protegidas como "islas de conservación", los incendios son contemplados como "intrusos" y "accidentes" en el interior de un ecosistema. Son "depredadores", tal y como los catalogaba la prensa en 1998.

En general, predomina la idea de que los incendios brotan cada año debido a una dinámica espontánea y excepcional, bajo una perspectiva que anula la posibilidad de pensar en constantes geográficas, climáticas y socio-ecológicas. Es decir, que no contempla la presencia de dinámicas cíclicas o con alguna razón de regularidad. Asimismo, existe cierta tendencia a la criminalización inmediata, pero anónima y generalizante, sin sanción penal, de las causas y de los causantes de los incendios. Es usual que las noticias concentren la culpa sobre la acción humana, pero es poco frecuente que se logre aclarar las circunstancias en las cuales se inició y propagó el incendio, más allá de indicar que surgió debido a "prácticas descuidadas" de la quema, del papel de los cazadores o de algún piromaníaco. En otras palabras, si bien se criminaliza el fenómeno, no se ahonda en sus factores sociales y ecológicos, como tampoco en los actores involucrados.

En el contexto de dicha penalización, se asume que los incendios forestales deben evitarse y suprimirse por completo. De esta manera, a pesar de la poca claridad que existe respecto a las circunstancias que explican el fenómeno, se plantea una política de gestión del fuego radical y contundente. Finalmente, no deja de sorprender que un fenómeno con tales características reciba una atención mediática por encima de la que recibe otro fenómeno semejante: la quema de los cañales para la zafra. En Costa Rica, como en buena parte de América Latina, el fuego es utilizado como un medio para facilitar la corta de la caña, sobre todo en grandes plantaciones, propiedad de grupos empresariales. Si bien este fenómeno tiene un conocido impacto ambiental y social, así como en la salud de los trabajadores y las poblaciones vecinas, la noticia de la quema de la caña no compite en atención con los incendios forestales. 


\section{Propuesta de ANÁlisis}

El objetivo de este artículo es analizar el régimen de incendios en el Bosque Tropical Seco de Costa Rica desde una perspectiva histórica, tomando a la provincia de Guanacaste como la unidad administrativa en estudio. La investigación pretende profundizar la dimensión temporal de algunos de los principales elementos que conforman el régimen de incendios actualmente predominante en dicha región. Nuestra premisa es que este régimen es el resultado de la interacción compleja entre procesos de cambio biofísico y biocultural, ocurridos a lo largo del siglo XX e inicios del siglo XXI. Es, por tanto, el producto de remanentes de paisajes ganaderos, de cambios ecológicos y de prácticas culturales del pasado, tanto como de las nuevas dinámicas que han surgido alrededor de la expansión de las áreas protegidas, el conflicto territorial y la recurrencia de las variaciones climáticas extremas. El artículo cuenta con cuatro secciones. La primera sección presenta la metodología y la base teórica del estudio. La segunda parte muestra el panorama general de los incendios forestales en Costa Rica entre 1998 y el presente. La tercera sección analiza los componentes históricos del régimen de incendios en el Bosque Tropical Seco de Costa Rica, focalizando su atención en los ciclos de expansión ganadera, en las prácticas sociales de uso del fuego, en los conflictos por la tierra y en el auge de la conservación de bosques durante la segunda mitad del siglo XX. La cuarta sección ofrece unas breves reflexiones.

Esta es una investigación enmarcada en la praxis de la Historia Aplicada. Además del trabajo en archivos y fuentes primarias, conllevó la realización de giras de campo, así como la organización de talleres y reuniones de trabajo con las y los habitantes de las comunidades en estudio. Fue también una investigación de base interdisciplinaria, sustentada en la construcción colectiva del conocimiento, la cual implicó el intercambio y la colaboración con campesinos y brigadistas contra incendios, especialistas en Ecología del Fuego, autoridades nacionales en incendios forestales y expertos en control de incendios del Área de Conservación Guanacaste, así como del Parque Nacional Barra Honda. 


\section{EL FUEGO DESDE UNA PERSPECTIVA INTERDISCIPLINARIA}

Este artículo analiza el fenómeno del fuego mediante la apropiación de herramientas teóricas y metodológicas provenientes de la Historia Ambiental, la Historia del Fuego y la Ecología del Fuego. La Historia Ambiental, como es sabido, explica los cambios ocurridos en el tiempo en tres dimensiones de la actividad humana: primero, en las transformaciones en el ambiente "material", es decir, en el estudio del impacto de la actividad humana sobre la Naturaleza y en sentido inverso: en el efecto del cambio ambiental en el cambio social. Segundo, en los "esfuerzos conscientes" del ser humano por regular sus relaciones con la Naturaleza mediante la acción política que define, normaliza y normativiza dichas relaciones. Tercero, en los constructos sociales, pensamientos e ideologías recreados en función de explicar y describir los vínculos de los grupos humanos con el ambiente ${ }^{15}$.

La Historia del Fuego estudia las interacciones existentes entre el fuego y la actividad humana en el largo plazo, analizando el impacto de dicha relación en términos sociales y ecológicos, como también simbólicos. Este campo define al fuego como un reorganizador de las estructuras ecológicas, de los paisajes, así como de los ciclos de energía y de nutrientes ${ }^{16}$. Lo comprende como una "biotecnología interactiva" que evidencia la compleja dependencia existente entre los ecosistemas y la sociedad humana a través de la historia ${ }^{17}$. En otro sentido, lo asume como un instrumento revelador de poder en cuanto a su capacidad para la transformación del medio, bien para la caza y la recolección, bien para las actividades agropecuarias, constituyendo un sustrato de diversos sistemas socioeconómicos. Pero también lo considera en función de su capacidad para la destrucción intencional del medio, asociada con el conflicto social y territorial. El control del fuego es un ejercicio de poder $^{18}$. Desde dicho campo, el fuego es entendido, además, como un articulador social, presente desde el acto mismo de la alimentación y del resguardo en el hogar, hasta en los rituales y prácticas que sustentan una creencia religiosa o espiritual de escala masiva. Existen, por ello, múltiples "universos morales" y simbólicos alrededor

\footnotetext{
15 John McNeill, The Historiography of Environmental History (Inglaterra: The Oxford History of Historical Writing, 2011) 5, 159. Manuel González de Molina, M. (2003). "La historia ambiental y el fin de la 'utopía metafísica' de la modernidad”, Aula-Historia Social (España) 12 (2003), 18-42.

16 Pyne, Fire, 15-16.

17 Pyne, Fire, 16.

18 Johan Goudsblom, Fire and Civilization (EE.UU-Inglaterra: Allan Lane-The Penguin Press, 1992).
} 
del fuego. En síntesis, detrás de la historia del fuego pueden encontrarse nuevas evidencias y materiales para la historia de las relaciones entre el ser humano y el ambiente ${ }^{19}$.

La Ecología del Fuego, por su parte, comprende al fuego como un elemento más en un contexto ecológico determinado ${ }^{20}$. Este campo de estudio plantea una crítica a los enfoques tradicionales que sugieren que, en la actualidad, los incendios son provocados por los seres humanos y que, en consecuencia, en "condiciones naturales" no deberían ocurrir. Asimismo, que el resultado de la acción del fuego es la devastación y la destrucción de un ecosistema, sin tomar en cuenta las dinámicas de largo plazo desde el punto de vista de la recuperación de las plantas y especies en general, así como de los efectos que ello puede tener sobre la biodiversidad de un ecosistema. La Ecología del Fuego, además de contextualizar el fuego en un marco ecológico (que no social, se advierte desde ahora), plantea que éste ha sido un factor de presión en la evolución de las especies y de las plantas en particular ${ }^{21}$.

\section{EL RÉGIMEN DE INCENDIOS COMO ESLABÓN METODOLÓGICO}

Aun sus identidades contrastadas, el concepto de "régimen de incendios" permite integrar los objetivos de la Historia Ambiental, la Historia del Fuego y la Ecología del Fuego, funcionando a la manera de una interfaz. Para Pausas, dicho régimen consiste en "el conjunto de características de los incendios en un área o ecosistema determinados y a lo largo de un período de tiempo, especialmente en referencia a la frecuencia, intensidad, estacionalidad y tipo de incendio" ${ }^{22}$. Dicho concepto introduce un importante elemento para el análisis histórico: la noción de cambio temporal en la comprensión del fuego como fenómeno socio-ecológico. Esta noción está relacionada con el "cambio global" que ocurre en un régimen de incendios como resultado de una variación extrema en la relación entre cinco factores en particular: la población, la temperatura, la deforestación y fragmentación, la presencia de plantas "invasoras" o "exóticas" y el abandono rural. Estos factores, a su vez,

\footnotetext{
19 Stephen J. Pyne, World Fire. The Culture of Fire on Earth (University of Washington Press, 1997), 12-16.

${ }^{20}$ Mark Cochrane, Tropical Fire Ecology. Climate Change, Land Use and Ecosystem Dynamics (Springer, 2009).

21 Juli Pausas, "Evolutionary fire ecology: lessons learned from pines". Trends in Plant Science 20 (5) (2015), 318-324.

22 Juli Pausas, Incendios forestales. Una visión desde la Ecología (Madrid: CSIC-Catarata, 2012).
} 
inciden en variables como las igniciones, la inflamabilidad, así como la existencia de combustible o biomasa. En otros términos, un régimen de este tipo es un sistema en el que una modificación en la relación entre estos factores puede explicar el aumento o la disminución de los incendios en un ecosistema durante un período determinado (Esquema 1).

La población determina las igniciones, es decir, las posibilidades de que un ser humano provoque un incendio ${ }^{23}$. La temperatura determina la inflamabilidad, es decir, la facilidad de generar la llama e iniciar un fuego. La deforestación y la fragmentación del paisaje favorecen (o afectan) la existencia de combustible (biomasa), indispensable para que ocurra un incendio. La relación entre estos elementos y el fuego es, sin embargo, compleja: la deforestación puede favorecer los incendios al abrir portillos para el avance de las llamas. Pero, a su vez, una tala radical del bosque disminuye el combustible posible por quemar. Finalmente, las plantas "invasoras" o "exóticas" y el abandono o despoblamiento del campo favorecen la acumulación de combustible, como puede ser el caso del abandono de pastizales en antiguas zonas ganaderas.

Cada ecosistema cuenta con su propio régimen de incendios, de la misma forma que cada régimen de incendios tiene su propio contexto histórico, es decir, socio-ecológico. Si se observa de nuevo el esquema, se constatará que los factores que los ecólogos del fuego han identificado como fundamentales en un régimen de incendios, corresponden con conceptos y procesos sociales que están presentes en el taller cotidiano de la investigación histórica. La variable "población" seguramente es entendida por los ecólogos desde un punto de vista cuantitativo, relativo a la presión poblacional por unidad de superficie. Sin embargo, también puede leerse en una forma ampliada, entendido como la relación "tierra-ser humano", que a su vez puede ser traducido a un concepto aún más general como, por ejemplo, "régimen de tenencia de la tierra".

\footnotetext{
${ }^{23}$ En Costa Rica, si bien abundan los rayos, debido a las condiciones climáticas se considera que la causa de los incendios es predominantemente antrópica. Véase: Andrea L. Koonce; Armando González-Cabán, "Social and Ecological Aspects of Fire in Central America", en: Goldammer J.G. (eds), Fire in the Tropical Biota. Ecological Studies (Analysis and Synthesis), 84 (1990), 135. https://doi.org/10.1007/978-3-642-75395-4_9
} 
Figura 1. Régimen de incendios y cambio socioecológico

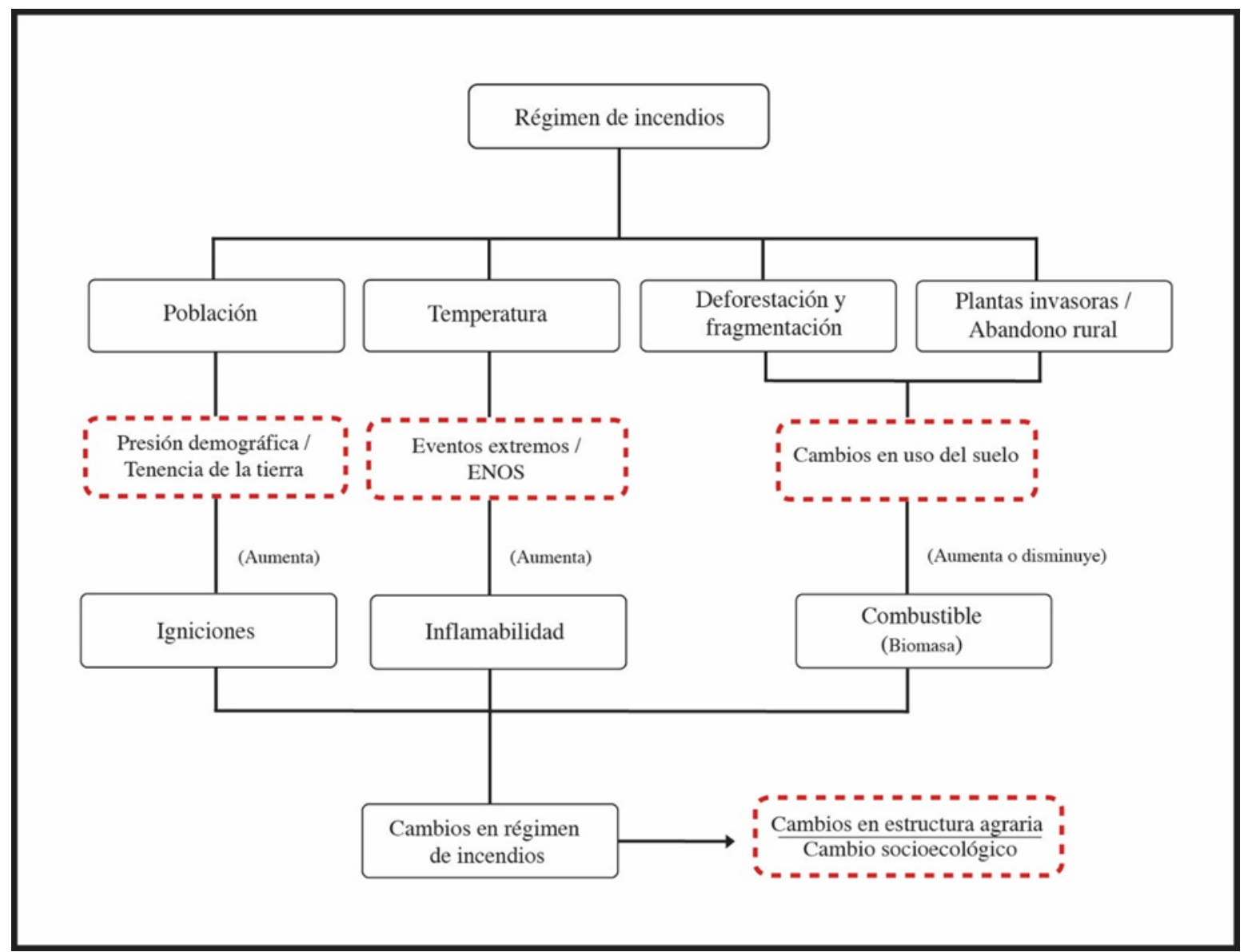

Fuente: Los autores a partir de: Pausas, Incendios, 102.

Hay poco que decir sobre la variable "temperatura" y su relación con ENOS. Sin embargo, las variables de "deforestación", "fragmentación del paisaje", "plantas invasoras" y "abandono rural", corresponden con procesos que la Historia Agraria y la Historia Ambiental han estudiado desde hace algún tiempo, tales como "régimen de uso del suelo" (tal y como se definía en los censos agrarios de la época desarrollista) o bien, más recientemente entendido, "dinámicas territoriales". Finalmente, el cambio global en el régimen de incendios que preocupa al ecólogo, puede interpretarse como un cambio en lo que se solía denominar como la "estructura agraria", esto es, en el sistema de relaciones sociales y agroecológicas, constituidas en torno al uso, propiedad y tenencia de la tierra. Todo régimen de incendios tiene una trama socioecológica. 


\section{INCENDIOS FORESTALES EN COSTA RICA}

Los incendios forestales en Costa Rica se concentran en la costa del Pacífico y, en particular, en la provincia de Guanacaste, en el noroeste del país. Como se puede apreciar en el Mapa 1, en esa provincia se encuentra la mayor densidad de incendios, identificados mediante imágenes satelitales, durante el período comprendido entre 2001 y 2012. Las estadísticas de la Comisión Nacional sobre Incendios Forestales y del Sistema Nacional de Áreas de Conservación confirman la representatividad de este mapa: a lo largo de dos décadas, entre 1998 y 2018, cerca del 75 por ciento de las tierras afectadas por incendios en Costa Rica estaban situadas en dicha región. Una segunda región de importancia es el sector suroeste de la Cordillera de Talamanca, cercana con la frontera con Panamá y, en menor medida, las tierras que rodean el humedal de Caño Negro, en la frontera con Nicaragua.

La evolución de la cantidad de hectáreas quemadas en Costa Rica desde 1998 es fluctuante (Gráfico 1) ${ }^{24}$. 1998 sigue siendo el año con mayor afectación, superando las 60 mil hectáreas, seguido por 2001 y 2016, cuando dicha cifra estuvo por encima de las 50 mil hectáreas. En promedio, cada año, desde 1998, se han quemado en Costa Rica poco más de 30 mil hectáreas. Existe una correspondencia entre los picos en la curva de tierras quemadas y el desarrollo de los fenómenos El Niño Oscilación del Sur. Cuando impera una fase cálida de El Niño, y dominan las altas temperaturas tanto como la sequía, se presentan las condiciones óptimas para que el fuego se extienda. Los años de 1998 y 2016 son buenos ejemplos de ello ${ }^{25}$. Pero, en otro sentido, cuando ocurren los eventos de La Niña y abundan las lluvias, la biomasa se recupera con facilidad y su acumulación favorece la propagación del fuego durante la siguiente temporada seca. En términos de incendios, ambos ciclos están vinculados entre sí.

Otra manera de comprender la dinámica del fuego en el territorio de Costa Rica consiste en contraponer el mapa de los incendios con mapas de temperatura, población y deforestación en escala nacional, tres de los factores causales de mayor

\footnotetext{
24 Las estadísticas sobre incendios forestales en Costa Rica están disponibles, con confiabilidad, a partir de 1998. Es importante indicar que, en el caso costarricense, se define como un incendio forestal a la afectación del fuego sobre los árboles y el bosque en general, tanto como sobre pastizales y áreas en barbecho ("Charrales" y tacotales).

25 Esteban Montero Sánchez, "Climatología del período 1997-2015 y su relación con los incendios forestales en un sector del Pacífico Norte". (Informe de investigación, Universidad Nacional: Heredia, 2017).
} 
importancia según el esquema de régimen de incendios ${ }^{26}$. El Mapa 2 ilustra la relación entre la distribución de los incendios y el promedio del déficit de precipitación anual durante sequías en diferentes regiones de Costa Rica entre 1960 y 2005. Es notorio que la concentración de incendios en Guanacaste coincide con el hecho de ser la región que reporta históricamente el mayor porcentaje de déficit de lluvia anual, lo que agrava su vulnerabilidad ante el fuego.

\section{Mapa 1. Distribución de incendios forestales en Costa Rica entre 2001 y 2012}

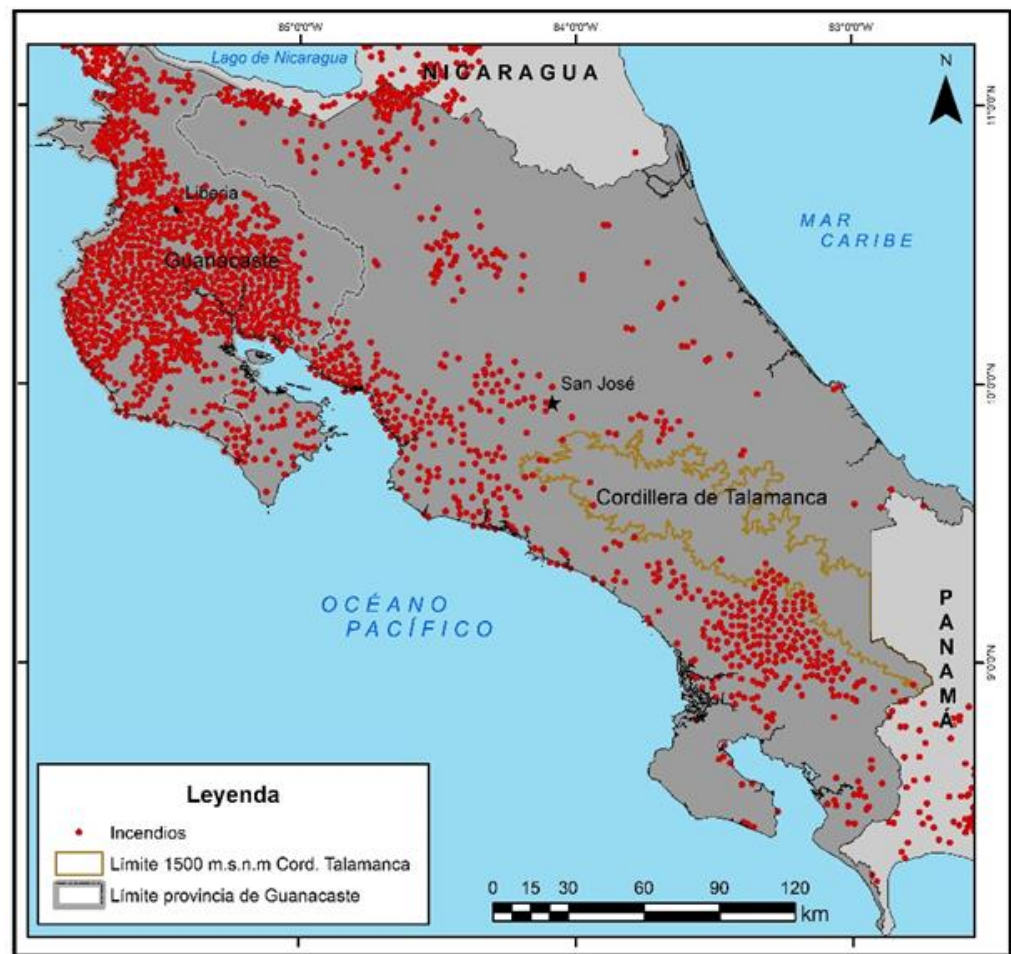

Fuente: Los autores a partir de: Juli Pausas, Incendios forestales: ¿desastre o biodiversidad? (Nicoya, Costa Rica: Conferencia presentada en la Sede Regional Chorotega-Universidad Nacional, 8 de mayo de 2013).

\footnotetext{
${ }^{26} \mathrm{Si}$ bien los datos de dichos mapas refieren, en algunos casos, a años distintos a la información sobre incendios, al tratarse de procesos estructurales y de cambio lento, como la temperatura, la presión demográfica o los focos de deforestación, se asume que la información contenida marca una tendencia representativa.
} 
Gráfico 1. Área afectada por incendios forestales en Costa Rica entre 1998 y 2019. (En hectáreas)

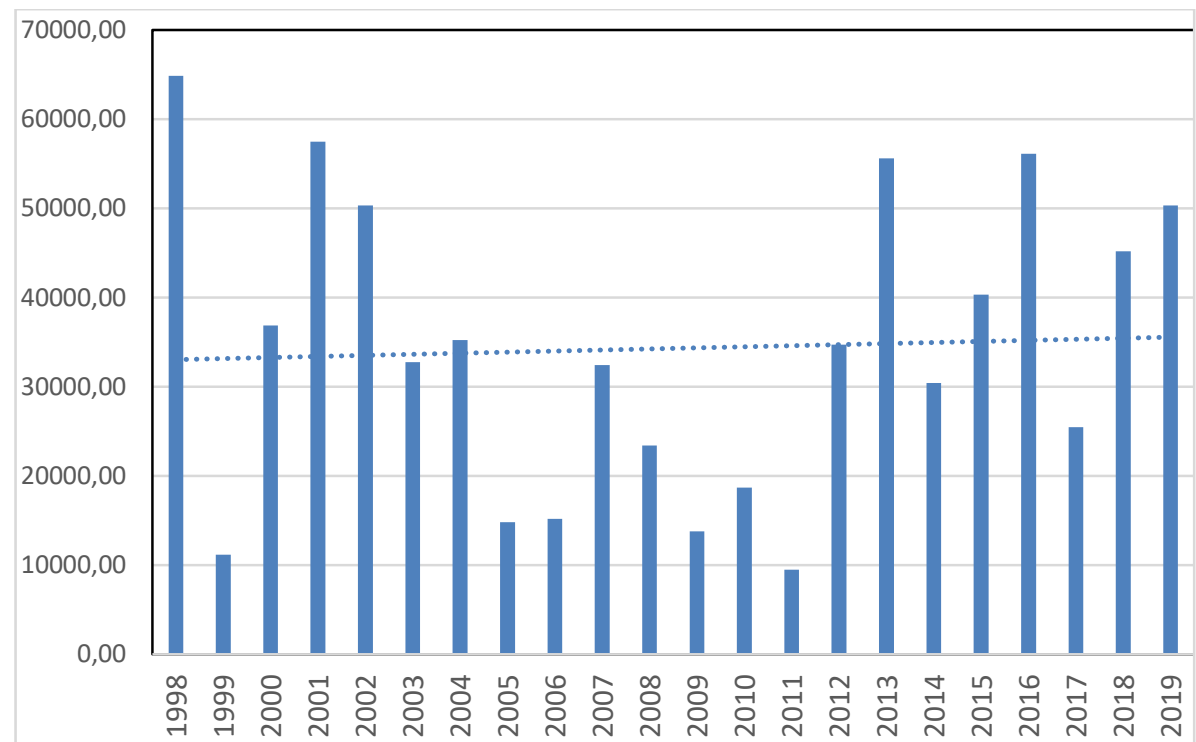

Fuente: Comisión Nacional de Incendios Forestales y Sistema Nacional de Áreas de Conservación, Costa Rica

\section{Mapa 2. Incendios forestales y déficit de precipitaciones en Costa Rica}

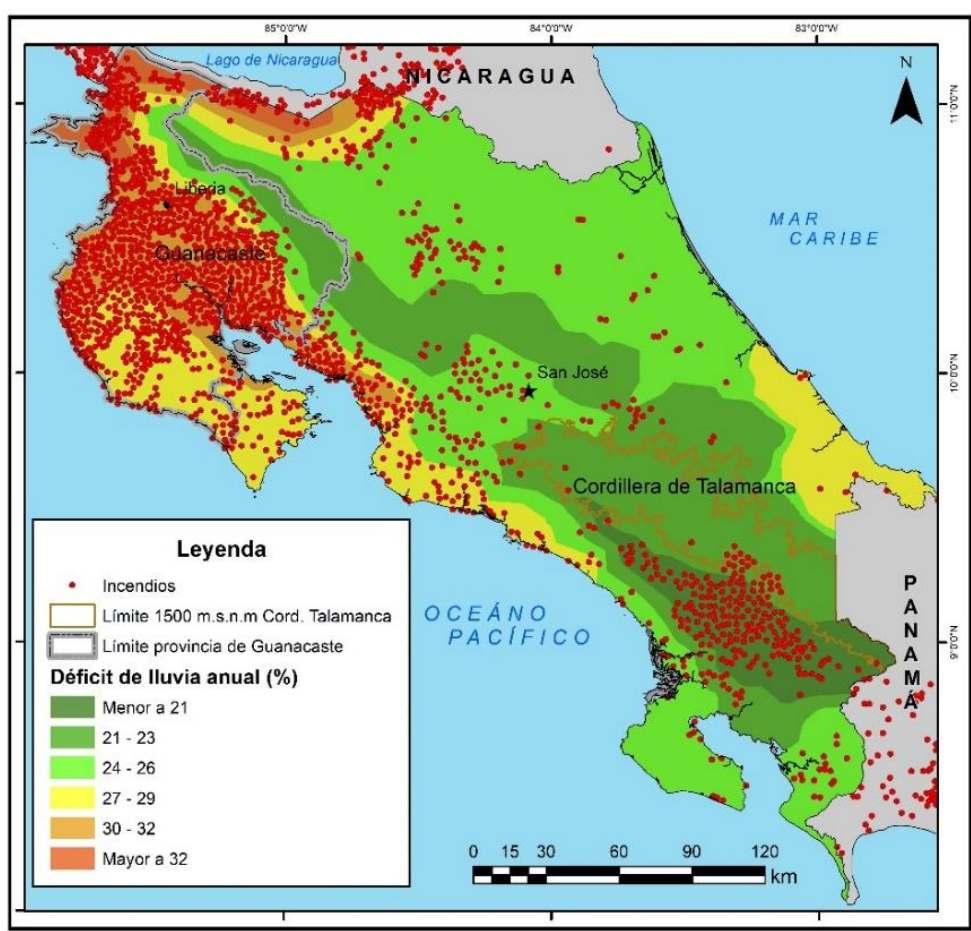

Fuente: Los autores a partir de: Instituto Meteorológico Nacional, Clima, variabilidad y cambio climático en Costa Rica (San José, Costa Rica: IMN, 2008) 
El Mapa 3 entremezcla los incendios con la distribución de la población en el territorio nacional, según la proyección realizada por Rosero y Bonilla para el año 2000. El mapa muestra que no hay una correlación directa entre presión demográfica e incendios. Las dos regiones con una mayor concentración de eventos (Guanacaste y las tierras que bordean la Cordillera de Talamanca, al sur del país) tienen una presión demográfica baja. Sin embargo, lo importante es pensar el dato demográfico desde un punto de vista cualitativo, no tanto en el sentido de la "presión" por unidad de superficie, sino más bien en el sentido de la relación tierra-ser humano, en este caso en particular, vinculando la concentración de los incendios con diferentes tipos de estructura de tenencia de la tierra. En Guanacaste, por ejemplo, existe una importante distribución de incendios en zonas fronterizas entre parques nacionales, tierras privadas y asentamientos campesinos, éstos últimos, creados por el Estado a partir de la década de 1970. Mientras que en el caso de la Cordillera de Talamanca, dicha distribución ocurre en las zonas fronterizas entre territorios indígenas (creados a finales de la década de 1970), parques nacionales y tierras privadas. En estas regiones, pareciera que la densidad que importa es aquella relativa a la concentración de puntos de conflicto social y territorial.

La relación entre deforestación e incendios es compleja (Mapa 4). Como ocurre en otras latitudes, a través de la historia el fuego ha sido una herramienta útil para agricultores de frontera y ganaderos con el objetivo de talar el bosque y abrir pastizales. Sin embargo, a partir de 1980 y, sobre todo, en las últimas dos décadas, no parece existir una relación fuerte entre incendios y deforestación en Costa Rica. En Guanacaste, la región más activa en incendios, antes que deforestación, en las últimas décadas lo que ha ocurrido es una recuperación de la cobertura boscosa gracias a la ampliación de las áreas protegidas. Para tener una idea, en dicha provincia, entre 1984 y 2014, el área cubierta por bosques pasó de cerca de 78 mil hectáreas en 1984, a poco más de 200 mil en 2014 ${ }^{27}$. La situación es diferente en el sector suroeste de la Cordillera de Talamanca, donde los incendios y los focos de deforestación coinciden en el mismo territorio.

\footnotetext{
27 D.G.E.C, Censo Agropecuario 1984 (San José, Costa Rica, 1987), 48-49; INEC, VI Censo Nacional Agropecuario 2014, https://www.inec.cr/censos/censo-agropecuario-2014 (Última revisión: 291 2021). Y: Julio César Calvo-Alvarado et al., "Deforestation And Forest Restoration in Guanacaste, Costa Rica: Putting Conservation Policies in Context", Forest Ecology and Management, 258 (2009), 931-940.
} 


\section{Mapa 3. Incendios forestales y presión demográfica en Costa Rica}

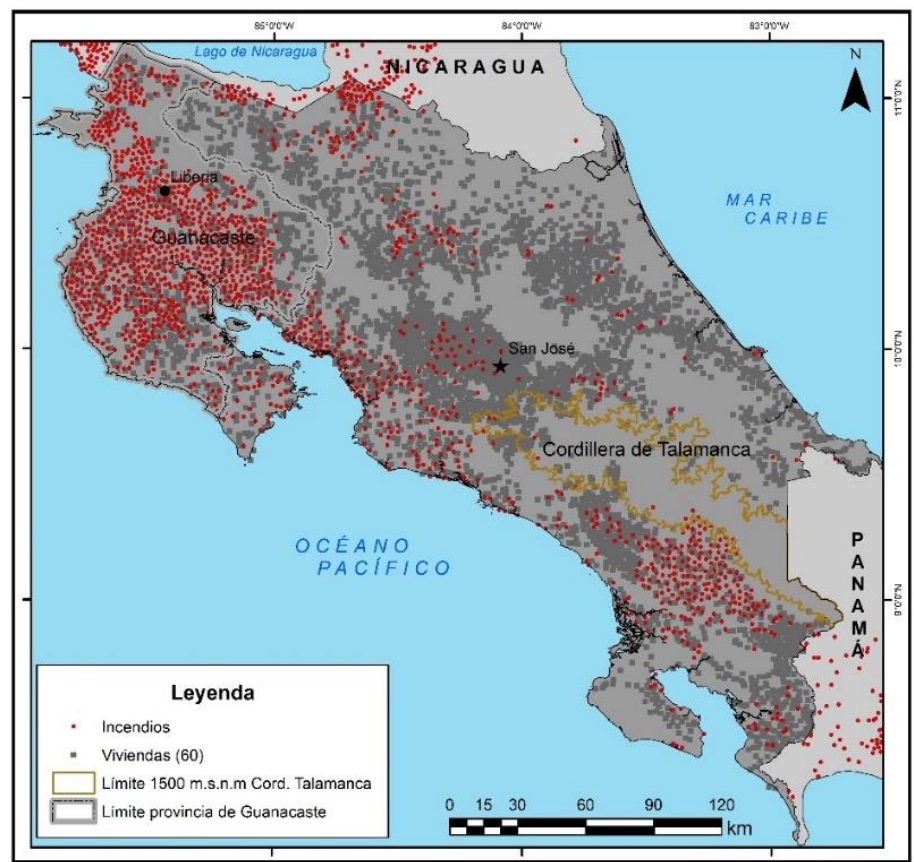

Fuente: Los autores a partir de: Roger Bonilla-Carrion; Luis Rosero-Bixby, Presión demográfica sobre los bosques y áreas protegidas, Costa Rica 2000. En Rosero Bixby, L. (Editor) "Costa Rica a la luz del censo del 2000" (San José, Costa Rica: Centro Centroamericano de Población de la Universidad de

Costa Rica-Proyecto Estado de la Nación-Instituto de Estadística y Censos, 2204), 564-582.

Mapa 4. Incendios forestales y focos de deforestación en Costa Rica

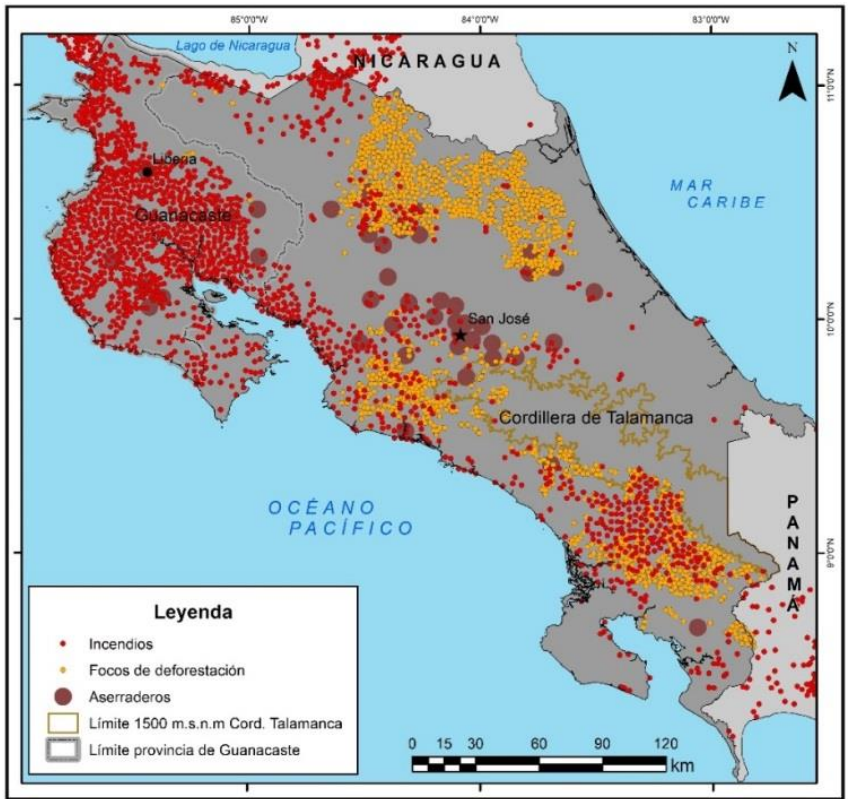

Fuente: Los autores a partir de: Ana Calvo; Edgar Ortiz, "Fragmentación de la cobertura forestal en Costa Rica durante los períodos 1997-2000 y 2000-2005". Revista Forestal Mesoamericana Kurú, 9

(22), (Junio de 2012): 10-21. 


\section{RÉGIMEN DE INCENDIOS EN EL BoSQUe TROPICAL SECO: UNA PERSPECTIVA DE LARGO PLAZO}

El Bosque Tropical Seco, de acuerdo con Janzen, se extendió en el pasado a lo largo del Pacífico de Mesoamérica, desde México hasta Panamá, cubriendo más de 500 mil kilómetros cuadrados. Sin embargo, como producto de la actividad humana, a finales de la década de 1980 apenas se conservaba un dos por ciento de dicha extensión en forma relativamente inalterada y, menos aún de ese porcentaje, bajo alguna condición de protección ${ }^{28}$. En la actualidad, este bosque comprende cerca de 100 mil hectáreas en la provincia de Guanacaste, en medio de un paisaje que entremezcla pastizales en uso y en abandono, áreas de regeneración natural y remanentes de bosque maduro (Mapa 5). Situado entre el nivel del mar y los 600 metros de altura, cuenta con una marcada estación seca, de cinco a siete meses al año, con un rango de precipitaciones entre $900 \mathrm{~mm}$ y $2400 \mathrm{~mm}$ durante la estación lluviosa. Es un ecosistema en el que predominan las especies caducifolias, con un rango inferior de temperatura promedio entre 16 y 23 grados centígrados, y superior de 26 a 38 grados centígrados ${ }^{29}$.

28 Daniel Janzen, Guanacaste National Park: Tropical Ecological And Cultural Restoration (UNED: Costa Rica, 1988), 11.

29 Janzen, Guanacaste, 19-29. 
Mapa 5. Áreas de Bosque Tropical Seco en Costa Rica y Centroamérica

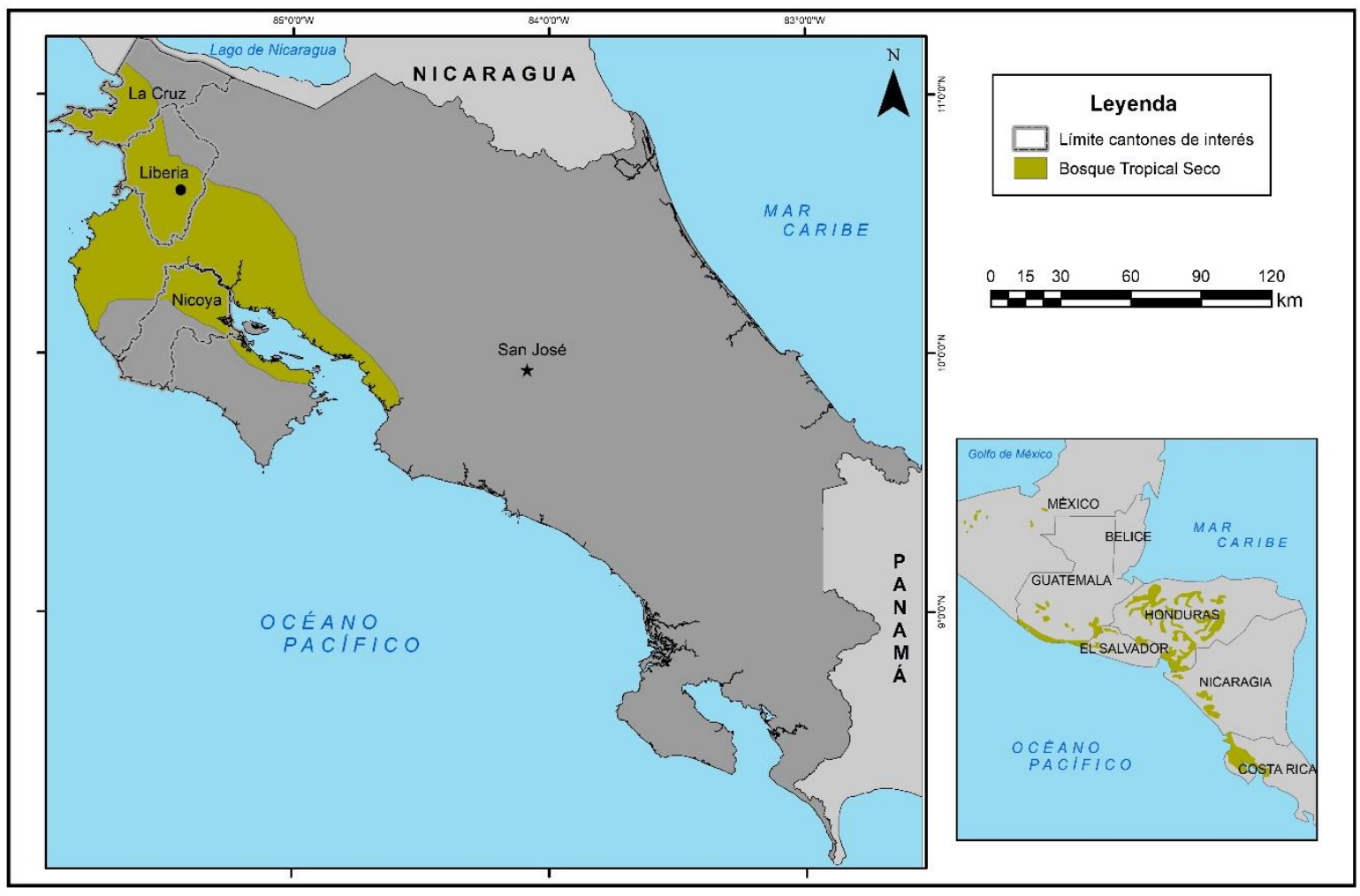

Fuente: Los autores a partir de: Lenin Corrales et al, "An overview of forest biomes and ecoregions of Central America". En: Chiabai, A. (Ed). Climate change impacts on tropical forests in Central America (New York, Estados Unidos. The Earthscan Forest Library Series, 2015), 17-38.

En este medio se han desarrollado los grandes procesos económicos y sociales que ha experimentado Guanacaste a lo largo de su historia ${ }^{30}$. En sus sabanas tuvo lugar el auge exportador de carne vacuna hacia Estados Unidos después de la Segunda Guerra Mundial ${ }^{31}$, de la misma forma que se desarrolló la Revolución Verde en el cultivo del arroz en la década de $1970^{32}$. Asediado por la deforestación desde tiempos coloniales, la recuperación de este ecosistema a partir de la década de 1980 ha simbolizado los esfuerzos nacionales en la creación de las áreas silvestres protegidas. Muchos de los parques nacionales más emblemáticos de Costa Rica se encuentran allí. No menos importante que esto, este ha sido uno de los principales espacios para la

\footnotetext{
30 Patricia Clare, "Cambios y continuidades en los sistemas productivos del Pacífico norte de la actual Costa Rica, 1450-1900" (Tesis de Doctorado, Universidad Pablo de Olavide: Sevilla, España, 2021).

31 Marc Edelman, The Logic of the Latifundio: The Large Estates of Northwestern Costa Rica Since the Late Nineteenth Century (Stanford University Press: EE.UU, 1992)

32 Wilson Picado Umaña, "Las buenas semillas. Plantas, capital genético y Revolución Verde en Costa Rica". Historia Ambiental Latinoamericana y Caribeña (HALAC). Revista De La Solcha, 2 (2) (2013): 308-337. En: https://www.halacsolcha.org/index.php/halac/article/view/295
} 
expansión de la economía del turismo en Costa Rica desde la década de 1990, bajo el modelo de turismo masivo de playa y de aventura ${ }^{33}$.

Como se indicaba páginas atrás, el Bosque Tropical Seco es el principal ecosistema afectado por el fuego en Costa Rica. Entre 1998 y 2018, más de 350 mil hectáreas se han quemado en su entorno. Este es un fenómeno que muestra una serie de patrones y regularidades, que sugieren la existencia de un régimen de incendios particular $^{34}$. Obsérvese, para ello, las tendencias que surgen de la información recopilada por los expertos del Área de Conservación Guanacaste, relativa a 398 incendios sucedidos entre 1998 y $2014^{35}$. En primer lugar, según estos datos, se trata de incendios concentrados en el tiempo y en el espacio. Casi un setenta por ciento de los eventos ocurrieron en dos meses del año, marzo y abril, los meses en los cuales imperan las altas temperaturas y la sequía. Como es de suponer, la mayor parte de estos incendios iniciaron durante las horas más intensas de sol, entre el mediodía y la tarde. De igual manera existe una concentración territorial: más de 70 por ciento de los eventos se situaron, en forma recurrente, alrededor de las mismas áreas protegidas y en los mismos distritos, y cerca de un 30 por ciento ocurrieron en una decena de sitios y parajes.

Las causas de los eventos son engañosamente diversas. Los expertos han tipificado cerca de quince posibles causas: un 20 por ciento de éstas se asocian con quemas descontroladas de pastizales o charrales, mientras que un porcentaje muy bajo se vincula con accidentes casuales. Sin embargo, más de un 60 por ciento de los incendios fueron provocados por acciones o motivos que revelan no solamente un uso consciente e intencional del fuego como "elemento destructivo", sino que además muestran la existencia de un conflicto entre actores sociales con distintas "tradiciones" de utilización de los bosques y, en un sentido general, con diferentes

\footnotetext{
${ }^{33}$ Maximiliano López López, "Conservación y dinámica territorial en Costa Rica, de 1950 al presente", en: Raúl Fonseca et al., Cruce de caminos. Lecturas disciplinarias del territorio (FLACSO: San José, Costa Rica, 2020), 43-68.

${ }^{34}$ La investigación sobre los regímenes de incendios en Guanacaste, y en Costa Rica en general, aún se encuentra en desarrollo y ameritará, sin lugar a dudas, un trabajo conjunto e interdisciplinario entre campos como la Biología, la Ecología, la Historia Ambiental y la Geografía, entre otras tantos posibles. Algunos estudios recientes para el Bosque Tropical Seco son: Gabriela Jones Román; Benjamín Álvarez Garay, "Dinámica de incendios en el Área de Conservación Guanacaste 1997-2017: perspectivas ecológicas para el manejo integral del fuego". Revista Perspectivas Rurales (Costa Rica), V. 16, N. 31 (2018). Y: Daniela Vargas Sanabria; Carlos Campos Vargas, "Modelo de vulnerabilidad ante incendios forestales para el Área de Conservación Guanacaste, Costa Rica". Cuadernos de Investigación UNED (Costa Rica), V. 10 (2) (Diciembre de 2018), 435-446.

35 Julio Díaz; Didi Guadamuz, "Base de datos de incendios forestales en el Área de Conservación Guanacaste. 1998-2014" (Programa Manejo Integral del Fuego-Área de Conservación Guanacaste: Costa Rica).
} 
culturas de apropiación del territorio. Dentro de este 60 por ciento sobresalen causas relacionadas con la actividad de la caza, la "venganza", el "vandalismo" o la quema "intencional", entre otras. Finalmente, la mayor parte de las tierras afectadas por el fuego han sido pastizales, sabanas naturales, charrales y otras tierras asociadas con espacios en sucesión ecológica ${ }^{36}$. Los bosques representan entre un 10 y 15 por ciento del total, aproximadamente ${ }^{37}$.

Un régimen de incendios se desarrolla en el tiempo, influenciado por grandes variables estructurales como el cambio territorial, el modelo económico o las variaciones climáticas extremas. No es una realidad biofísica que surge de pronto. Para comprenderlo, la construcción de datos fiables y de largo plazo resulta una labor indispensable. Pero, asimismo, un régimen de este tipo se desarrolla sobre sustratos socio-ecológicos y socio-culturales, asociados con la historia del paisaje tanto como con las prácticas culturales relativas al fuego, vigentes entre una población. Las relaciones entre seres humanos y plantas a lo largo de décadas o siglos constituyen la base de la formación de los paisajes o, dicho en otros términos, dichas relaciones explican el rol de la biomasa en un sistema socioeconómico, así como el conjunto de prácticas socialmente establecidas y legitimadas para su control. Un régimen de incendios es un proceso biofísico como también biocultural.

En este sentido, el actual régimen de incendios en el Bosque Tropical Seco es una "huella" dejada por las coyunturas de cambio económico y social sucedidas, a distintos ritmos y en distintos contextos históricos, a lo largo de un siglo. Por una parte, la importancia de los pastos como zonas de quema en el presente, lleva a pensar en la formación histórica de los pastizales en esta región, en el sentido ecológico, es decir, acerca del tipo de forrajes introducidos; en el sentido cultural, relativo a su manejo y simbolismo social, así como en el sentido económico respecto a su vinculación con los sistemas ganaderos. Por otra parte, la excepcional recurrencia espacial de los incendios y su origen humano, claramente intencional, obliga a repasar la evolución histórica, así como las causas de los conflictos sociales y territoriales de la región.

\footnotetext{
36 Jones, Dinámica de incendios, 65.

${ }^{37}$ Esta es una estimación hecha a partir de los datos nacionales.
} 


\section{AFRICANIZACIÓN DEL PAISAJE ${ }^{38}$ Y CICLO SOCIAL DEL FUEGO}

En el siglo XX, Guanacaste experimentó un primer auge ganadero entre las décadas de 1920 y $1950^{39}$. Se trataba de una economía ganadera dirigida al consumo nacional, que además de la producción de novillos y vacas, constituía una extensa vía de tránsito del ganado que se importaba desde Nicaragua. A pesar de la escasez de mano de obra, la actividad pecuaria creció significativamente en los siguientes años, respaldada, en parte, por las inversiones de ricos comerciantes y cafetaleros provenientes del Valle Central de Costa Rica, convertidos en hacendados, así como debido a las medidas proteccionistas dictadas por el Estado, que afectaron las importaciones desde Nicaragua ${ }^{40}$. Una prueba de este avance es el hecho de que en 1950 esta región contaba con el hato de mayor tamaño del país, compuesto por más de 230 mil cabezas ${ }^{41}$.

Lo que parece haber sido un gran despegue productivo, fue además un rediseño del paisaje de la región, así como una resignificación del fuego como elemento de antropización. Diferentes autores, contemporáneos y de la época, sugieren que dicha expansión ganadera ocurrió, en gran medida, gracias a la introducción de pastos "exóticos", que mejoraron la nutrición del ganado, a la vez que ayudaron a los hacendados a enfrentar la ausencia de forraje durante las continuas sequías $^{42}$. Dichos pastos eran forrajes provenientes de África, los cuales ingresaron al continente americano desde tiempos coloniales a través de Brasil y las Antillas, siguiendo las rutas de la plantación y de la esclavitud ${ }^{43}$. Entre estos pastos se destacaban el "jaragua" (Hyparrhenia rufa (Nees.) Stapf), el "guinea" (Panicum

\footnotetext{
38 James J. Parsons, "Spread of African Pasture Grasses to the American Tropics", Journal of Range Management (1972), 16.

39 Jorge León, Historia Económica de Costa Rica en el siglo XX. Tomo II: La economía rural (San José, Costa Rica: IICE-CIHAC, Universidad de Costa Rica, 2012), 103.

${ }^{40}$ Lowell Gudmundson, "Apuntes para una historia de la ganadería en Costa Rica, 1850-1950", Revista de Ciencias Sociales (Costa Rica) 17-18 (1979): 66-70. León, Historia económica, 125.

${ }^{41}$ Dirección General de Estadística y Censos, Censo Agropecuario de 1950 (San José, Costa Rica, 1953), 92.

42 Gudmundson, Apuntes, 72.

43 Parsons, Spread, 12-17.
} 
máximum), "pará" (Brachiaria mutica), "gordura" o calinguero (Melinis minutiflora P. Beauv) y el "kikuyo" (Pennisetum clandestinum) ${ }^{44}$.

De todos, el jaragua fue el gran colonizador de los pastizales de Guanacaste. Esta es una especie ideal para la ganadería de engorde en condiciones de sequía. En regiones con poca lluvia se recomienda el pastoreo cuando la planta tiene unos 60 centímetros de altura y un buen contenido de hojas. El jaragua no permite la invasión de otras especies, pero tiene la desventaja que su maduración excesiva genera tallos leñosos y poco nutritivos para el ganado, urgiendo por ello el retoño de tallos nuevos ${ }^{45}$. Cuando esto sucede, para el ganadero la forma más práctica para renovar el pastizal consiste en quemarlo, justo antes de las lluvias de mayo. El siguiente relato, incluido en una práctica agronómica realizada en Guanacaste en 1942, describe este proceso:

"Es costumbre muy general, cuando se aproxima el invierno, poner fuego a las plantaciones y regar luego la semilla que tiene gran poder germinativo: puede permanecer por largo tiempo en el suelo germinando en cualquier oportunidad. Pude apreciar como la semilla almacenada, se hincha con el calor, rompiendo los sacos en que es almacenada"46.

Además,

"La siembra se hace por semilla y al voleo. Es conveniente darle una limpia cuando está pequeño por la competencia que se establece con las malas hierbas. Resiste bien el fuego. En verano muy prolongado se encuentra aparentemente seco, aunque conserva gran cantidad de savia en la parte central del tallo y el exterior de él es muy

\footnotetext{
${ }^{44}$ Henri Pittier, Plantas usuales de Costa Rica (San José, Costa Rica: Editorial Costa Rica, 1978): 273; José Feo, "Forrajes (Una opinión)", Boletín de Fomento (Costa Rica) 1 (Enero de 1911), 44-45; Tomás Carrasquilla, "Un buen forraje. El calinguero", La Escuela de Agricultura (Costa Rica) 1, N. 3 (Marzo de 1929), 40-41; "El rey de los forrajes: el calinguero", La Escuela de Agricultura (Costa Rica) 2, N. 3 (Marzo de 1930), 64-65; Sixto Alberto Padilla, "El célebre pasto brasileño Androp gón Rufus (jaragua)", Boletín de Fomento (Costa Rica) 9 (Octubre de 1911), 660-669.

${ }^{45}$ Oscar Agreda, Efectos del fotoperíodo y variabilidad en el pasto jaragua - Hyparrhenia rufa (Nees.) Stapf - (Turrialba, Costa Rica: IICA-Centro Tropical de Investigación y Enseñanza de Graduados, 1961). R. Daubenmire, "Ecology of Hyparrhenia rufa (Nees) in Derived Savanna in NorthWestern Costa Rica", British Ecological Society (Inglaterra) 9, N. 1 (abril 1972), 11-23.

46 Luis Jones Vargas, Informe de práctica para obtener el grado de Bachiller en Ciencias Agrícolas (Escuela Nacional de Agricultura, Costa Rica, 1942), 14.
} 
leñoso impidiendo que el ganado lo coma. Por este motivo no se presta para quemarlo sino después de dos o tres meses de buen verano, en día calmado, es decir, que no sople mucho viento para que arda despacio hasta la raíz y entonces se producen retoños de gran fuerza que en dos meses o menos, según el terreno, ya se le puede echar el ganado" ${ }^{\prime 7}$.

\section{Mapa 6. Rutas de expansión de los pastos “Jaragua” y "Calinguero” en América}
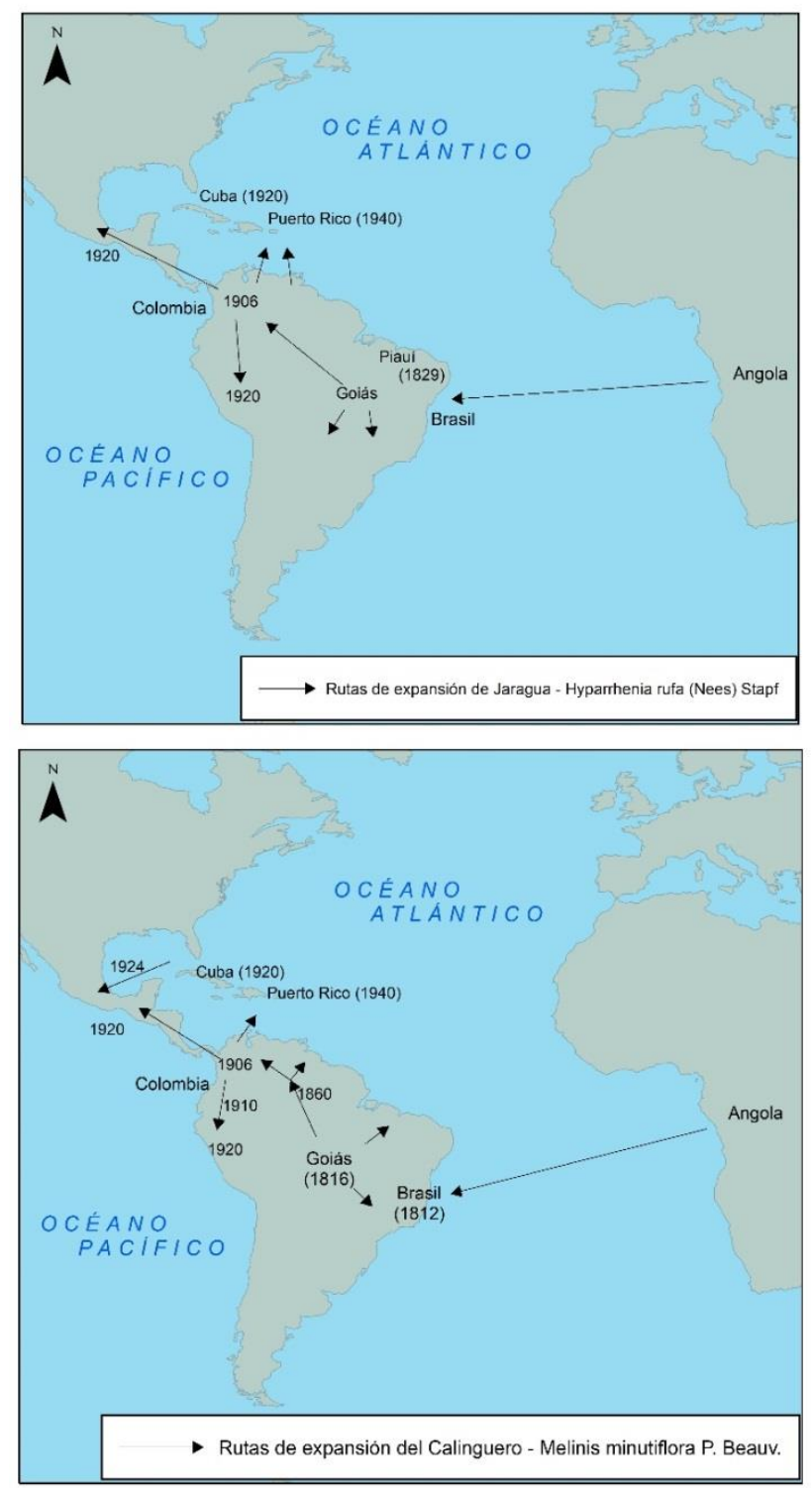

Fuente: Los autores a partir de: James J. Parsons, "Spread of African Pasture Grasses to the American Tropics". Journal of Range Management (1972), 12-17.

\footnotetext{
47 Jones, Informe, 14-15.
} 
El jaragua no solamente era resistente al fuego, sino también tenía un alto poder germinativo, dos características que estaban vinculadas con su pasado africano. Como lo han señalado los expertos, el rendimiento y la resistencia al pastoreo de estos pastos ha sido el resultado de la selección evolutiva que experimentaron, durante miles de años, en su foco de origen. Por un lado, las poblaciones de herbívoros silvestres de las sabanas africanas presionaron la evolución a favor de especies más resistentes al pisoteo y al consumo intensivo. Y, por el otro, cuando se desarrolló el pastoreo, esta práctica favoreció la evolución de las especies que se adaptaron a las quemas de los pastizales, hechas en forma regular por los humanos ${ }^{48}$.

Entre las décadas de 1960 y 1980, Guanacaste pasó por un segundo boom ganadero, esta vez vinculado con la exportación de carne a Estados Unidos. La creciente demanda del producto en dicho mercado y las políticas estatales de diversificación productiva, propiciaron las condiciones adecuadas para el mejoramiento técnico de la producción ganadera tanto en su fase de campo como de procesamiento y comercialización ${ }^{49}$. Además de la introducción de nuevas razas y forrajes, se implementaron programas de Sanidad Animal y de manejo del hato en general, así como de fertilización de pastos ${ }^{50}$. Asimismo, se construyeron plantas empacadoras que integraron casi por completo la cadena, modernizando y asegurando la calidad en la exportación de la proteína. A pesar de estos cambios, la producción ganadera mantuvo su carácter extensivo, con una baja carga animal por superficie, a costa de un uso abierto de los pastizales. Mientras que en 1950, los pastos en Guanacaste abarcaban poco más de 260 mil hectáreas, en 1984 éstos habían aumentado a casi medio millón de hectáreas ${ }^{51}$. El dominio paisajístico del pastizal y del ganado era evidente en esta región: en 1984, había más de medio millón de cabezas de $\operatorname{ganado}^{52}$.

Como buen colonizador, el jaragua se adaptó bastante bien a estos cambios. Algunos estudios estimaron que, en la década de 1980, esta especie se extendía a

\footnotetext{
48 Jorge León Arguedas, Botánica de los cultivos tropicales (San José, Costa Rica: IICA, 2000), 432-433.

${ }^{49}$ Edelman, La lógica, 213-250.

50 Jorge León et al, Desarrollo tecnológico en la ganadería de carne (San José, Costa Rica: Consejo Nacional de Investigaciones Científicas y Tecnológicas, 1982), (4) 1 - (4), 58.

51 Dirección General de Estadística y Censos, Censo Agropecuario de 1950 (San José, Costa Rica, 1953), 57; Dirección General de Estadística y Censos, Censo Agropecuario de 1984 (San José, Costa Rica, 1987), 48.

52 Dirección General de Estadística y Censos, Censo Agropecuario de 1950 (San José, Costa Rica, 1953), 96. Dirección General de Estadística y Censos, Censo Agropecuario de 1984 (San José, Costa Rica, 1987), 122.
} 
través de unas 800 mil hectáreas en el país ${ }^{53}$. Otras investigaciones afirmaban que en la década de 1990 el jaragua ocupaba cerca de 780 mil hectáreas, es decir, más de un 40 por ciento del total de los pastos del país ${ }^{54}$; un porcentaje que subía hasta el 70 por ciento en Guanacaste.

\section{EXPANSIÓN GANADERA Y CONFIGURACIÓN DE UNA PIROCULTURA}

Las anteriores coyunturas ganaderas han sido atendidas por la historiografía agraria y social bajo enfoques teóricos y metodológicos que privilegian el análisis de la producción y de las dinámicas del capital. Sin embargo, lo que sugiere la "africanización" del paisaje de Guanacaste (dígase, del Bosque Tropical Seco) es que dichas coyunturas pueden ser ahora estudiadas desde nuevos prismas, centrados en fenómenos como la introducción de plantas "exóticas" al contexto tropical y sus consecuencias en el ciclo del fuego, como sucede en este caso en particular. En este sentido, una interpretación historiográfica alternativa diría que, además del surgimiento de una economía ganadera moderna, la historia de Guanacaste durante el siglo XX revela al mismo tiempo la formación de una "pirocultura", estructurada a partir de una planta de origen africano, dependiente del fuego para desarrollarse como especie y como forraje para el ganado.

Una pirocultura puede entenderse como un campo de prácticas sociales y de constructos simbólicos articulados alrededor del fuego, vigentes durante un período de tiempo, en un territorio con características ecosistémicas y productivas particulares. Las prácticas sociales están vinculadas con actividades y procesos productivos de un sistema socioeconómico específico, en el que son legítimas, o mejor dicho, son legitimadas, gracias a su utilidad para la reproducción de dicho sistema. Los constructos simbólicos refieren a las construcciones semióticas en el lenguaje popular asociadas con el fuego, a representaciones sociales del paisaje, entre

\footnotetext{
${ }^{53}$ Rocío Saborío López, Diagnóstico sobre el comportamiento de la actividad ganadera. Período 1974-1984 (San José, Costa Rica: SEPSA-IICA, 1985), 5

54 Gonzalo Cortés, Atlas Agropecuario de Costa Rica (San José, Costa Rica: Editorial de la Universidad Estatal a Distancia - EUNED, 1994), 434.
} 
otras, las cuales contribuyen a "normalizar" al fuego, y a "la quema" en particular, como un fenómeno socio-ecológico recurrente en un entorno territorial ${ }^{55}$.

Es cierto que la quema es una práctica de larga data en el ecosistema del Bosque Tropical Seco ${ }^{56}$. Pero, al igual que el régimen de incendios, una pirocultura está compuesta por elementos particulares, que le otorgan una dinámica diferenciada respecto a otras prácticas o piroculturas en el pasado (o en otros contextos ecosistémicos). En Guanacaste, el fuego, el jaragua y la ganadería de carne formaron, durante el siglo XX, un triángulo socio-ecológico novedoso, con un evidente impacto económico y social. El fuego contribuyó a viabilizar un gran sistema económico y político basado en la producción de proteína para el mercado nacional e internacional, cuyas rentas alimentaron el poder de las elites locales y nacionales, ampliando la desigualdad social, a expensas de la combustión del tejido vegetal de los pastizales y los bosques ${ }^{57}$.

La quema fue una "tecnología biofísica" bien aprovechada por los ganaderos con grandes extensiones de pastos y tierras en barbecho. Pero su uso excesivo generó conflictos entre éstos y los pequeños agricultores, que el Estado trató de resolver, sin muchos resultados, mediante legislaciones puntuales. En el siglo XIX y en los inicios del XX, se emitieron decretos y leyes que buscaban controlar el problema estableciendo penas y multas, así como regulaciones para la quema controlada. Se creó la figura de "celadores" para que recorrieran los caminos, vigilando las quemas que se hacían en las "rondas" (bordes) de las vías. La legislación, en efecto, estaba pensada no solo para evitar los conflictos entre vecinos debido a los incendios descontrolados, sino también en función del cuidado de los pastos que rodeaban los caminos, los cuales alimentaban a los bueyes, caballos y ganado en general que transportaban, durante largas jornadas, las mercancías y los productos agrícolas ${ }^{58}$.

El Estado intentó regular las rondas mínimas para la quema, fijando además un protocolo de comunicación entre vecinos y autoridades. La ronda afectaba los

\footnotetext{
${ }^{55}$ Frank Niele, Energy: Engine of Evolution (Amsterdam: Elsevier, Shell Global Solutions, 2005), 29-50. Y: Fátima Braña Rey, Imaginarios de monte y fuego. Los incendios forestales en Galicia. Imagonautas (España), 6 (2015), 15-26.

56 Gilbert Vargas, Sabana arbustiva del Parque Nacional Santa Rosa, 1928-2004 (San José, Costa Rica: CEMEDE-Universidad Nacional, 2005).

57 James J. Parsons, Forest to Pasture: Development or Destruction? Revista de Biología Tropical (Costa Rica) 24 (1976), 121.

58 Véase: Decreto N. XLVII de 9 de febrero de 1844; Decreto N. XXIII de 20 de junio de 1854; Ley N. 121 de 26 de octubre de 1909. Sobre los "celadores", véase: Archivo Nacional de Costa Rica, Fomento 3798.
} 
intereses de los pequeños campesinos, debido a que recortaba el terreno disponible para el cultivo. Era de por sí una carga de trabajo y un control más para este tipo de agricultor, dependiente de la roza y quema para la siembra de granos. Esto conllevó al desacato de la legislación, como era de esperar. Se trataba, además, de leyes que se ejecutaban con desigualdad, con criterios ambiguos y dobles intenciones. Un ejemplo de esto puede evidenciarse en un escrito publicado en 1937, en un periódico regional de Guanacaste. Mencionaba el articulista el caso de los pequeños agricultores de granos de Cañas, en el sureste de la provincia, para quienes dicha ley era "inadecuada e impracticable". No solo significaba sacrificar buena parte de sus pequeñas parcelas para abrir las rondas, advertía, sino que también conllevaba muchas jornadas de trabajo. Se preguntaba, por otra parte, si la aplicación que el gobierno le exigía al Jefe Político no era sino más bien un pretexto para desalojar de sus tierras a la mayor parte de dichos agricultores, todos ellos, carentes de títulos, mal llamados entonces "parásitos" ".

Este mismo articulista defendía el uso del fuego como una herramienta productiva, a falta de medios modernos, para sostener las cosechas de maíz, frijol y arroz que salían de dicha región, alimentando "a miles de personas". Y, al mismo tiempo, lo presentaba como una arma para controlar la Naturaleza; como un medio para combatir las "plagas" de animales y de cuantas "alimañas" afectaban los campos de cultivo:

"Ejerce [el fuego] estas grandes ventajas: se limpia con facilidad la breña y la maleza; las alimañas se ahuyentan y se desinfectan los campos de ratas, garrapatas y culebras o serpientes. Si no fuera eso nuestros campos serían intransitables, invisibles en ellos los ganaderos, y sufrirían grandemente los cultivos si los hubiera, a consecuencia de las ratas que tan tremendos daños ocasionan en tiempos de peste"60

Así entendido, el fuego era un regulador ecológico y social del territorio, el cual marcaba las fronteras entre la agricultura y el bosque, entre el ornato de los cultivos y el caos del monte. Sobre todo para el agricultor de granos, pequeño por lo 
general, la quema era la forma más práctica de desmonte y de mantener sus cosechas protegidas del ataque de animales. Una preocupación que seguramente no compartía, a esas escalas, el gran ganadero, portador de una licencia no declarada para usar la quema con menores controles y mayores excepciones a la ley. El fuego era, en todo caso, parte ya del utillaje diario del agricultor y del ganadero, así como del paisaje mismo. La quema en Guanacaste, como se decía en una novela escrita en 1946, “...no era otra cosa que la más genuina expresión del ambiente natural de los llanos" ${ }^{\prime 61}$.

No siempre el fuego cumplía su rol socio-ecológico y productivo, bajo el aparente control de la gestión humana. La quema era también transgresora y delictiva, tal y como lo expresa el siguiente texto de 1907, citado por Edelman:

"El peor de los males porque adolece la Provincia del Guanacaste para el fomento de la industria pecuaria son los fuegos que se dan á los sitios sin que los hacendados lo puedan evitar, debido al poco respeto que existe para la propiedad, pues como es sabido en la mayor parte de las fincas se han situado ciertas gentes que todo su patrimonio es una escopeta para vivir de la cacería y no trabajar"62

El fuego emergía como un manifiesto de mundos e individuos que estaban al margen de esa sociedad y economía ganadera: "ladrones", "borrachos", merodeadores y cazadores. Para éstos, la quema de pastizales, a "destiempo", desobedeciendo quizás los ciclos de las lluvias y de la previsión, era un acto de transgresión a un sistema social en el cual estaban relegados por su condición de "vagos" o por su rechazo a convertirse en peones y en habitantes comunes de los pueblos y las haciendas.

\section{BIOMASA VEGETAL, BIOMASA SOCIAL: CONFLICTOS POR LA TIERRA Y CONSERVACIÓN DE BOSQUES}

El mosaico territorial sobre el cual se asentó esta pirocultura estaba dominado por el pastizal y los charrales. Para tener una idea de su peso, entre 1950 y 1960, los dos juntos acaparaban más de la mitad del área agrícola de la provincia de Guanacaste, mientras que, entre 1973 y 1984, momento cumbre de la ganadería extensiva, dicho porcentaje subió hasta el 70 por ciento. Tomando en cuenta los

\footnotetext{
61 Edelmira González Herrera, Alma llanera (Sin pie de imprenta, 1946).

62 Edelman, La lógica, 139.
} 
datos, atrás citados, sobre la extensión cubierta por el jaragua en la década de 1980, no es difícil imaginar la importancia que tenía el fuego para gestionar dichas tierras, más aún en las grandes propiedades. Por otra parte, la tierra dedicada al cultivo de granos mantuvo una tendencia de expansión hasta 1984, lo que supuso el uso del fuego para la preparación de los suelos, fuera para la siembra del frijol y el maíz en las laderas, fuera para el cultivo de arroz en las partes bajas y planas.

\section{Grafico 2. Evolución del uso del suelo en la provincia de Guanacaste entre 1950 y 2014}

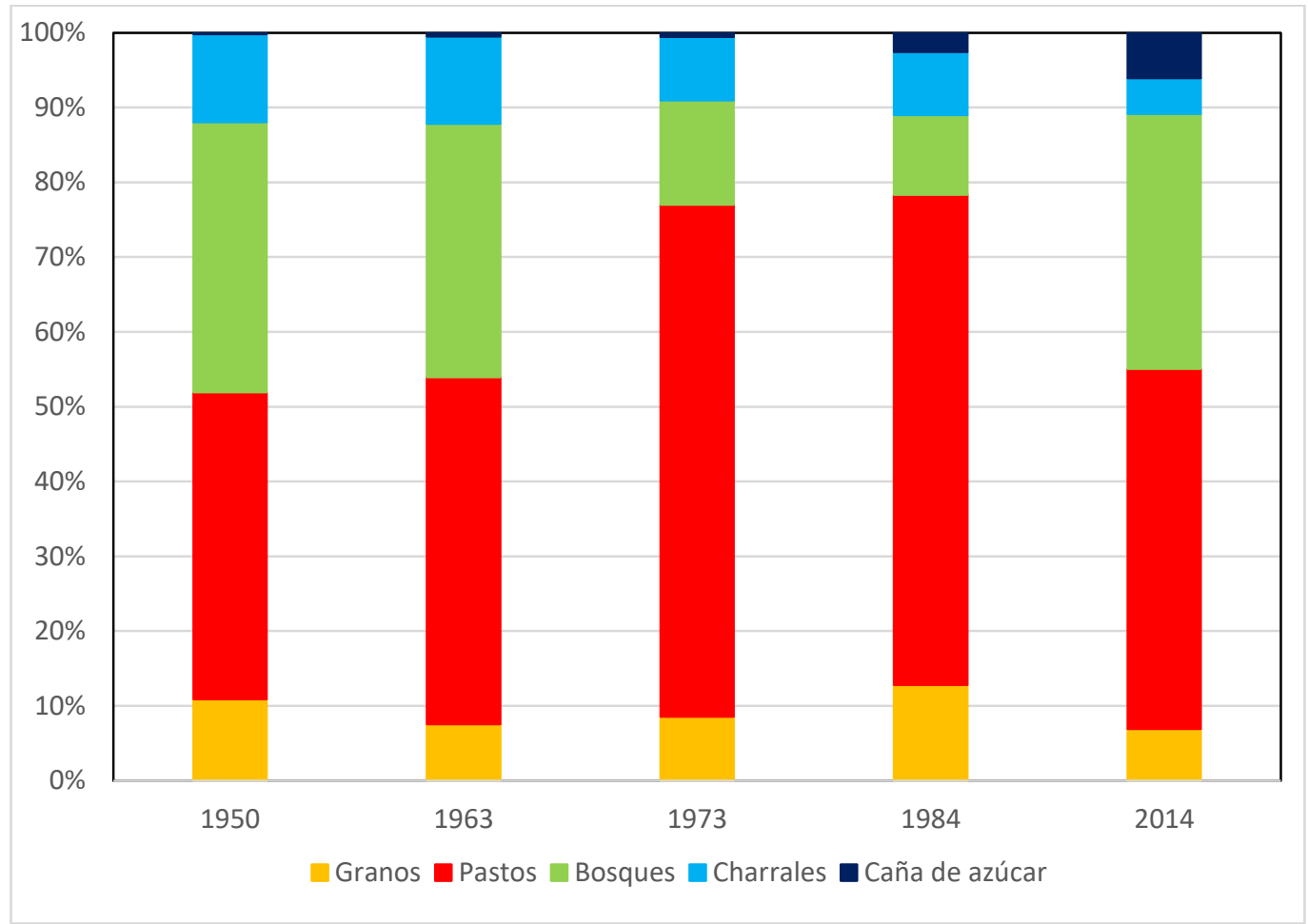

Fuente: D.G.E.C./INEC, Censos Agropecuarios de 1950, 1963, 1973, 1984 y 2014

El pastizal y el charral eran símbolos de una estructura de tenencia de la tierra desigual, con una elevada concentración, particularmente en el noroeste de la provincia. En 1973, en los cantones de Liberia y La Cruz (que contienen en el presente la mayor porción del Bosque Tropical Seco) imperaba una estructura de tenencia dominada por las grandes propiedades con 500 o más hectáreas de extensión. Estas propiedades controlaban más del 80 por ciento del total de la tierra. Si a éstas se sumaran las fincas con más de 100 hectáreas, el porcentaje se acercaría al 95 por 
ciento. En su mayor parte eran fincas cubiertas por pastizales, bosques y charrales, que reunían un hato de unas 130 mil cabezas y que entonces empezaban a cultivar el arroz en gran escala y mecanizado. Las fincas pequeñas, de base campesina, tenían una presencia puntual en este entorno ${ }^{63}$.

A todo lo largo del siglo XX, Guanacaste tuvo una amplia historia de conflictos por la tierra, violentos y recurrentes, que se agudizaron a partir de la década de 1960, con el cercamiento generalizado de las propiedades y el avance de las relaciones capitalistas en la producción agrícola y pecuaria ${ }^{64}$. La concentración de la tierra, el empobrecimiento, el desempleo y, en general, la proletarización del campesinado propiciaron el surgimiento de numerosas tomas ("invasiones") de fincas privadas y del Estado mediante grupos organizados y acciones espontáneas en distintas partes de la geografía provincial. Entre 1963 y 1980, hubo más de 800 "invasiones" de tierras en Costa Rica, abarcando más de 700 mil hectáreas; cerca de una cuarta parte de dichas tierras fueron tomadas en Guanacaste, es decir, casi 200 mil hectáreas ${ }^{65}$.

Al igual que en el resto de Costa Rica, el Estado respondió ante este problema en Guanacaste mediante la intervención del Instituto de Tierras y Colonización $(\text { ITCO })^{66}$. Este instituto, creado en el marco de la Carta de Punta del Este de 1961, tuvo como objetivo contener el conflicto agrario mediante dos políticas: primero, la formación de colonias con el objetivo de trasladar y albergar allí a las familias que habían tomado tierras, algunas de las cuales se situaron en Guanacaste como las colonias Las Lilas, Miravalles y San Juanillo ${ }^{67}$. Segundo, ante el fracaso del anterior modelo, el establecimiento de asentamientos campesinos, levantados en las mismas propiedades que habían sido tomadas, en los que se distribuía una parcela por cada familia.

A pesar de las limitaciones financieras y de contar con un entramado jurídico ambiguo, el impacto de ITCO fue evidente: mientras que en 1963 este instituto adquirió casi 5 mil hectáreas para distribuirlas entre los campesinos, dos décadas

\footnotetext{
${ }^{63}$ Carlos Rodríguez Solera, "Estructura agraria de Guanacaste y políticas estatales en el Distrito de Riego Arenal-Tempisque" (Tesis de Licenciatura en Sociología, Universidad de Costa Rica, 1988), 72-80.

64 Rodolfo González Carballo, Organización y luchas campesinas en Guanacaste 1950-1970 (Tesis de Licenciatura en Historia, Universidad de Costa Rica, 1982). Y: Edelman, La lógica, 137-175.

65 Beatriz Villarreal, "El precarismo rural en Costa Rica, 1960-1980" (Tesis de Maestría en Sociología, Universidad de Costa Rica, 1981 ), 84.

66 El ITCO fue creado en 1961, en el contexto de la Carta de Punta del Este (1961). Luego fue renombrado como Instituto de Desarrollo Agrario (IDA) y, más recientemente, como Instituto de Desarrollo Rural (INDER).

67 Instituto de Tierras y Colonización, Memoria Anual (San José, Costa Rica: ITCO, 1963-1968).
} 
después, en 1986, el acumulado de tierras compradas o que habían experimentado algún tipo de negociación entre el Estado, los campesinos y los propietarios directos, era de $663 \mathrm{mil}^{68}$. En Guanacaste, por ejemplo, se establecieron cerca de 90 asentamientos, abarcando más de 50 mil hectáreas. Solo en los cantones de Liberia y La Cruz, antes mencionados, se crearon 18 asentamientos, cubriendo más de 12 mil hectáreas ${ }^{69}$.

Al mismo tiempo que atendía el conflicto por la tierra, el Estado costarricense enfrentaba el problema de la deforestación. En las décadas de 1960 y 1970, mientras miles de campesinos tomaban tierras y abundaba la violencia tanto como la represión estatal, Costa Rica era el "paraíso de la deforestación", con tasas lineales que superaban las 30 mil hectáreas por año ${ }^{70}$. Esta fue una tendencia que Guanacaste replicó en forma radical: entre 1950 y 1984, se taló poco más de un 60 por ciento del bosque regional, a un ritmo estimado de entre 3 y 5 mil hectáreas al año ${ }^{71}$.

En un giro que ha generado un amplio debate, a partir de la década de 1990 Costa Rica empezó a revertir dicho patrón, dejando atrás las tasas de deforestación de la década de 1970. Algunos estudios estiman que, entre 1986 y 2000, el bosque se recuperó en el país a un ritmo de 17 mil al hectáreas año, mientras que lo hizo a 26 mil hectáreas anuales entre 2000 y 2005. En este último año, se calculaba que el territorio nacional estaba cubierto por bosques en un 48 por ciento ${ }^{72}$. En términos de conservación y, entendido en el largo plazo, esto ha significado que, de poco más de tres mil hectáreas protegidas a inicios de la década de 1970, se pasó a casi medio millón en 1986, hasta alcanzar, en 2012, más de un millón trescientas mil hectáreas

\footnotetext{
68 Jorge Mora, La distribución de la tierra y los asentamientos humanos en Costa Rica, en: Centroamérica y los problemas del desarrollo en el campo (Santiago de Chile, Chile: FAO, 1990), 97.

69 INDER, Caracterización del Territorio INDER Liberia-La Cruz, Costa Rica (San José, Costa Rica: Instituto de Desarrollo Rural, 2014 ), 56-57.

70 Samuel Pérez; Fernando Protti, Comportamiento del sector forestal durante el período 1950-1977 (San José, Costa Rica: Oficina de Planificación Sectorial Agropecuaria, 1978).

${ }^{71}$ Silvia Rodríguez; Emilio Vagas, El recurso forestal en Costa Rica. Políticas públicas y sociedad (Heredia, Costa Rica: Editorial de la Universidad Nacional, 1988), 31. La mayor parte de esta tala ocurría fuera de la ley: en 1977, para citar una año, el total nacional de los bosques explotados mediante permisos era solo de 19348 hectáreas. Véase: Anabelle Porras; Beatriz Villarreal, Deforestación en Costa Rica. Implicaciones sociales, económicas y legales (San José, Costa Rica: Editorial Costa Rica, 1993), 44-45.

72 Julio César Calvo-Alvarado, Bosque, cobertura y recursos forestales 2008. Informe Estado de la Nación. Capítulo Armonía con la Naturaleza (San José, Costa Rica: Programa Estado de la Nación, 2009), 2. Para una evaluación crítica sobre la "cobertura forestal" en Costa Rica, véase: Revista Ambientico (Costa Rica), N. 253 (mayo de 2015).
} 
protegidas, entre parques nacionales, refugios de vida silvestre y reservas forestales, entre otras formas de protección ${ }^{73}$.

Como se dijo antes, la extensión de bosques en Guanacaste pasó de cerca de 78 mil hectáreas en 1984, a poco más de 200 mil hectáreas en 2014. Los cambios más interesantes ocurrieron, sin embargo, en el detalle de esta tendencia. En primer lugar, la categoría de "Bosques explotados", que en 1984 abarcaba casi 20 mil hectáreas, desapareció en 2014. En segundo lugar, el "Bosque natural" aumentó su cobertura en unas 70 mil hectáreas en dicha provincia. En tercer lugar, entre ambos años hubo una disminución de los charrales a casi la mitad, lo que indica que el "uso" de estos terrenos como espacios de barbecho (para el cultivo de granos, por ejemplo) dejó de ser una práctica relevante y que el bosque se ha desligado de este tipo de interacciones con la agricultura y la ganadería. Finalmente, hubo un aumento de más de 40 mil hectáreas en tierras en reforestación y en regeneración natural ${ }^{74}$. Dicho lo anterior, es inobjetable que, en los últimos treinta años, el bosque sustituyó al pastizal como el elemento principal del patrón de uso del suelo en Guanacaste ${ }^{75}$. Pero es también un hecho que los asentamientos campesinos se convirtieron en un factor territorial relevante en la provincia.

\section{CAMPESINOS "PRECARISTAS" VERSUS CIENTÍFICOS CONSERVACIONISTAS}

La vecindad entre los asentamientos campesinos y las áreas protegidas en Guanacaste fue inevitable. Muchos de los asentamientos se crearon en zonas marginales de antiguas haciendas, en pastizales abandonados y en tierras que estaban al margen de la actividad productiva. Por ese motivo habían sido objeto de la "invasión" por parte de los campesinos. Y, debe decirse que, por esa misma razón, en no pocas ocasiones el mismo propietario, por lo general absentista, permitía e incentivaba la acción de los campesinos para negociar con el Estado la compra de las tierras. Algunos de los primeros parques nacionales y reservas biológicas se situaron

\footnotetext{
73 Wilson Picado; Elisa Botella, "Tenencia de la tierra y cambio territorial en Costa Rica (1950-2014), en: Raúl Fonseca et al., Cruce de caminos. Lecturas disciplinarias del territorio (FLACSO: San José, Costa Rica, 2020), 24.

74 D.G.E.C, Censo Agropecuario 1984 (San José, Costa Rica, 1987), 44. Y: INEC, VI Censo Nacional Agropecuario 2014, https://www.inec.cr/censos/censo-agropecuario-2014 (Última revisión: 2912021 ).

75 Claudia Tapia Arenas, Análisis del cambio de cobertura forestal 2005-2015 en Guanacaste, Costa Rica (Tesis de Licenciatura en Ingeniería Forestal, Instituto Tecnológico de Costa Rica, 2016).
} 
bajo esas mismas condiciones: en sectores que no eran de interés para la producción agropecuaria, que alguna vez fueron zonas de pastoreo, con parches de bosque y de difícil acceso para el transporte.

La proximidad fue, desde el inicio, conflictiva. Los parques nacionales fueron "territorios extraños" que se insertaron en medio de poblaciones con dinámicas territoriales y tradiciones en el uso de los bosques, que no se ajustaban a las lógicas de la conservación. En el caso de aquellos que fueron antes haciendas, el establecimiento de los parques rompía con la actividad de la caza que los vecinos habían practicado por años en los bosques ahora protegidos, de la misma forma que lo hacía con la costumbre de cultivar maíz y frijoles en las laderas. En nada ayudaba que en ocasiones el Estado no pagaba al antiguo propietario las tierras incluidas en la delimitación del parque: si bien esas tierras entraban a formar parte de un parque nacional, ante el impago prevalecía, de facto, el derecho de uso por parte de los dueños originales ${ }^{76}$.

La relación entre asentamientos campesinos y parques nacionales fue aún más complicada y, podría decirse que, competitiva. En las décadas de 1970 y 1980, algunos conservacionistas, es decir, funcionarios públicos y científicos (nacionales y extranjeros), no tenían una percepción positiva del campesino "precarista", tomador de tierras. Para éstos, el campesino era un "agente deforestador", que invadía la tierra y, una vez explotada, la vendía para emigrar a otras regiones ${ }^{77}$. Era un campesino antiecológico, "la mayor amenaza a la integridad de las áreas silvestres", como lo apuntaban unos expertos en $1988^{78}$. Esta perspectiva se agudizaba toda vez que los habitantes de los asentamientos aprovechan su cercanía con las tierras del parque para cazar, cultivar y alimentar el ganado en sus pastizales.

El problema trascendía el recelo existente entre unos y otros. La actitud de algunos de estos conservacionistas manifestaba el peso cada vez mayor que tenía la política de Conservación de bosques en la agenda nacional, del mismo modo que mostraba lo inverso: la pérdida de relevancia de la política de tierras a partir de la

\footnotetext{
76 Un buen ejemplo de esta situación es el Parque Nacional Barra Honda, situado en la Península de Nicoya, al sur de la provincia de Guanacaste. Véase: Luis Fernando Artavia Víquez, "Delimitación efectiva de parques nacionales, un caso de estudio: Parque Nacional Barra Honda, Costa Rica" (Tesis de Licenciatura en Geografía, Universidad de Costa Rica, 2008).

77 Luis Fournier, Desarrollo y perspectivas del movimiento conservacionista costarricense (San José, Costa Rica: Editorial de la Universidad de Costa Rica, 1991), 71.

${ }^{78}$ Alonso Ramírez; Tirso Maltodano, T. Desarrollo socioeconómico y el ambiente natural de Costa Rica. Situación actual y perspectivas (San José, Costa Rica: Fundación Neotrópica, 1988), 88.
} 
década de 1980. En 1987, vecinos de Colonia Bolaños, un asentamiento situado justo en el corazón del Bosque Tropical Seco, en el Área de Conservación Guanacaste, enviaron una carta al Instituto de Desarrollo Agrario (antes ITCO), revelando las presiones que estaban recibiendo de parte de un científico conservacionista para vender sus parcelas, con el objetivo de ampliar una reserva biológica. Se quejaban los vecinos que, aparte de que les ofrecía precios "ridículos", les amenazaba con denunciarlos ante la policía por deforestar, entre otras $\operatorname{cosas}^{79}$. Días después, un funcionario de este instituto confirmaba, en una breve nota que, en efecto, existía "un poco de presión" de parte del implicado, quien además había brindado información falsa a los campesinos acerca de una posible reubicación por parte del instituto ${ }^{80}$.

A través de este episodio se demostraba que, en dicho contexto, la parcela campesina y sus dueños eran menos importantes, para la ciencia conservacionista, que el bosque por proteger. Pero, asimismo, quedaba documentado que el modelo de conservación por el cual el país había apostado desde 1970, llevaba en su genética rasgos de conflicto social y territorial. Los incendios forestales en el presente son un producto de estas tensiones. Las numerosas causas identificadas como "vandalismo", "venganza", "intencional", "caza" o asociadas con la quema para el cultivo en los asentamientos, indican que el fuego continua siendo un elemento de transgresión social y de protesta, tanto como que la disputa y el juego de poder entre conservacionistas, funcionarios, campesinos de asentamientos y cazadores, está latente aún. No se trata, por tanto, solamente de la existencia de un régimen de incendios, sino además de un fenómeno de "incendiarismo".

\section{¿PARA QUÉ la Historia Del FUego?: A MANERA DE CONClusiones}

En el estudio de los incendios forestales, la historia importa. Un régimen de incendios se desarrolla sobre un paisaje y una estructura agraria que son el producto en el tiempo de las presiones de factores biofísicos como también bioculturales. Los jaraguales, que todavía bordean el Bosque Seco Tropical, remiten a un proceso de

\footnotetext{
79 Instituto de Desarrollo Agrario, Expediente 877, Carta, 19 de enero de 1987, 7 de noviembre de 1986, Folio 274-275.

80 Instituto de Desarrollo Agrario, Expediente 877, Memorandum, 5 de marzo de 1987, Folio 277; Instituto de Desarrollo Agrario, Expediente 877 , Memorandum, 8 de abril de 1987, Folio 279-280.
} 
intercambio y movimiento de especies vegetales a través del planeta, ocurrido varios siglos atrás. La articulación de esta especie con la actividad ganadera fue tal que se propició la formación de una pirocultura, de casi un siglo de duración. Por otra parte, los pastos abandonados, biomasa fácil para el fuego en el presente, evidencian la crisis que experimentó la economía ganadera de la región a partir de la década de 1980. Son también la muestra de una competencia territorial perdida del pastizal frente al bosque, debido a los cambios en la política económica y ambiental que vivió Costa Rica en las últimas décadas.

La recurrencia de los incendios desde el punto de vista espacial indica que, pese a que dicha pirocultura y su matriz territorial entraron en crisis hace mucho tiempo, existen remanentes y residuos de prácticas del fuego, así como de tradiciones de artificialización del paisaje y de caza, en las cuales el fuego tiene un papel central. Pero, a la vez, dichas prácticas sugieren que han surgido nuevas formas de "incendiarismo", es decir, del uso del fuego como arma de protesta individual o colectiva. Si bien no son comparables con aquellas que los "marginados" utilizaban para desafiar el sistema de poder del latifundio, obligan a pensar en las causas sociales que lo explican en el presente. Si más del 70 por ciento de los incendios ocurren en el entorno del Bosque Tropical Seco y si más del 70 por ciento de esos incendios se sitúan en los mismos espacios, el problema no es exclusivamente originado por piromaníacos o acciones individuales aisladas. Hay una trama social de fondo: la tensión territorial existente entre asentamientos campesinos, tierras privadas y parques nacionales así lo revela.

La política y la cultura ambiental en el país han cambiado significativamente en las últimas tres décadas. Las políticas de conservación de bosques surgieron en un momento en el cual el país, a pesar de que advertía la gravedad de la deforestación y del desigual acceso a la tierra, privilegió el crecimiento productivo mediante la tecnología de la Revolución Verde y escogió, a partir de la década de 1980, el modelo económico de la apertura comercial y la liberalización, relegando al sector rural a una posición secundaria y, diríase que, escénica, en el marco del auge turístico. Este es un elemento fundamental para entender las visiones contradictorias y, en ocasiones, ambiguas, que tiene la sociedad costarricense acerca de los incendios forestales y de 
los parques nacionales. Pensar en los parques nacionales como bosques "naturales", "vírgenes" o "inalterados", es un primer sesgo a evitar al momento de analizar la dinámica de los incendios forestales, de la misma forma que lo es ignorar la desigualdad y la pobreza que persiste en muchas poblaciones vecinas de estos parques.

Gran parte de la información y de los argumentos que se plantearon en este artículo surgieron en el campo, durante tres años de trabajo en la provincia de Guanacaste. La investigación supuso no solamente un trabajo académico convencional, centrado en el análisis de fuentes primarias en archivos, sino también implicó la organización de múltiples talleres con funcionarios públicos y habitantes de las comunidades. Las entrevistas, así como las visitas a fincas privadas y parques nacionales fueron dos herramientas metodológicas igualmente importantes. Los incendios forestales constituyen un tema en el cual la construcción participativa del conocimiento es indispensable. Y en el que se originan, con una regularidad nada despreciable, "momentos de Ciencia Posnormal", en los cuales queda muy claro que las y los expertos forestales y ambientales, las agricultoras y agricultores, así como las comunidades en general, disponen de un acervo de conocimientos cuya consideración enriquece y mejora la calidad del dato construido por la ciencia en archivo y desde las estadísticas oficiales.

Gracias a la organización de giras con estudiantes de grado en Historia y en Enseñanza de la Historia de la Universidad Nacional, también quedó claro que este es un tema que debe formar parte de la agenda curricular de nuestro país como parte de un proceso de construcción de ciudadanías ecológicas críticas. En un contexto de cambio climático, y en un país que ha apostado por la protección de los bosques, es un acto mínimo de sensatez discutir acerca de los riesgos que enfrentaremos en el futuro, con tal biomasa acumulada, ante sequías y posibles conflictos sociales en el campo. Si bien la Historia no es la "maestra de la vida", en cuanto a los incendios forestales tiene al menos un buen cuaderno de apuntes del pasado que nos ayuda a comprender mejor el presente. 


\section{AGRADECIMIENTOS}

Este artículo es un producto del proyecto de investigación "El Bosque Seco en llamas. Memoria e historia del uso del fuego en Guanacaste, Costa Rica", bajo financiamiento (obtenido mediante concurso) del Fondo Institucional de Desarrollo Académico (FIDA), de la Universidad Nacional, Costa Rica.

\section{REFERENCIAS}

Agreda, Oscar, Efectos del fotoperíodo y variabilidad en el pasto jaragua Hyparrhenia rufa (Nees.) Stapf - (Turrialba, Costa Rica: IICA-Centro Tropical de Investigación y Enseñanza de Graduados, 1961).

Artavia Víquez, Luis Fernando, Delimitación efectiva de parques nacionales, un caso de estudio: Parque Nacional Barra Honda, Costa Rica (Tesis de Licenciatura en Geografía, Universidad de Costa Rica, 2008).

Bonilla-Carrion, Roger; Rosero-Bixby, Luis, Presión demográfica sobre los bosques y áreas protegidas, Costa Rica 2000. En Rosero Bixby, L. (Editor) "Costa Rica a la luz del censo del 2000" (San José, Costa Rica: Centro Centroamericano de Población de la Universidad de Costa Rica-Proyecto Estado de la Nación-Instituto de Estadística y Censos, 2204), 564-582.

Braña Rey, Fátima, Imaginarios de monte y fuego. Los incendios forestales en Galicia. Imagonautas (España), 6 (2015), 15-26.

"Brasil impotente ante el fuego", La Nación (Costa Rica), 22 de marzo de 1998, 19A.

Calvo-Alvarado, Julio César, Bosque, cobertura y recursos forestales 2008. Informe Estado de la Nación. Capítulo Armonía con la Naturaleza (San José, Costa Rica: Programa Estado de la Nación, 2009).

Calvo-Alvarado, Julio César et al., "Deforestation And Forest Restoration in Guanacaste, Costa Rica: Putting Conservation Policies in Context", Forest Ecology and Management, 258 (2009), 931-940.

Calvo, Ana; Ortiz, Edgar, "Fragmentación de la cobertura forestal en Costa Rica durante los períodos 1997-2000 y 2000-2005". Revista Forestal Mesoamericana Kurú, 9 (22), (Junio de 2012), 10-21.

Carrasquilla, Tomás, "Un buen forraje. El calinguero", La Escuela de Agricultura (Costa Rica) 1, N. 3 (Marzo de 1929), 40-41.

Cochrane, Mark, Tropical Fire Ecology. Climate Change, Land Use and Ecosystem Dynamics (Springer, 2009). 
Comisión Centroamericana de Ambiente y Desarrollo, Actas de la reunión Problemas y perspectivas en materia de incendios en América Central (Honduras, 1998).

Clare, Patricia, "Cambios y continuidades en los sistemas productivos del Pacífico norte de la actual Costa Rica, 1450-1900" (Tesis de Doctorado, Universidad Pablo de Olavide: Sevilla, España, 2021).

Corrales, Lenin et al., "An overview of forest biomes and ecoregions of Central America". En: Chiabai, A. (Ed). Climate change impacts on tropical forests in Central America (New York, Estados Unidos. The Earthscan Forest Library Series, 2015), 17-38.

Cortés, Gonzalo, Atlas Agropecuario de Costa Rica (San José, Costa Rica: Editorial de la Universidad Estatal a Distancia - EUNED, 1994).

Díaz, Julio; Guadamuz, Didi, "Base de datos de incendios forestales en el Área de Conservación Guanacaste. 1998-2014" (Programa Manejo Integral del Fuego-Área de Conservación Guanacaste: Costa Rica).

Daubenmire, R., "Ecology of Hyparrhenia rufa (Nees) in Derived Savanna in NorthWestern Costa Rica", British Ecological Society (Inglaterra) 9, N. 1 (abril 1972): 11-23.

Edelman, Marc, The Logic of the Latifundio: The Large Estates of Northwestern Costa Rica Since the Late Nineteenth Century (Stanford University Press: EE.UU, 1992).

Estrada Alvarado, Rocío, “Arde Guanacaste”, La República (Costa Rica), 1998, 5A.

Feo, José, "Forrajes (Una opinión)", Boletín de Fomento (Costa Rica) 1 (Enero de 1911): 44-45.

Fournier, Luis, Desarrollo y perspectivas del movimiento conservacionista costarricense (San José, Costa Rica: Editorial de la Universidad de Costa Rica, 1991).

"Fuego devora Amazonas", La Nación (Costa Rica), 20 de marzo de 1998, 18A.

González Carballo, Rodolfo, Organización y luchas campesinas en Guanacaste 19501970 (Tesis de Licenciatura en Historia, Universidad de Costa Rica, 1982).

González Herrera, Edelmira, Alma llanera (Sin pie de imprenta, 1946).

González de Molina, Manuel, "La historia ambiental y el fin de la 'utopía metafísica' de la modernidad", Aula-Historia Social (España) 12 (2003), 18-42.

Goudsblom, Johan, Fire and Civilization (EE.UU-Inglaterra: Allan Lane-The Penguin Press, 1992).

Gudmundson, Lowell, "Apuntes para una historia de la ganadería en Costa Rica, 18501950", Revista de Ciencias Sociales (Costa Rica) 17-18 (1979), 66-70.

INDER, Caracterización del Territorio INDER Liberia-La Cruz, Costa Rica (San José, Costa Rica: Instituto de Desarrollo Rural, 2014). 
Instituto Meteorológico Nacional, Clima, variabilidad y cambio climático en Costa Rica (San José, Costa Rica: IMN, 2008).

Janzen, Daniel, Guanacaste National Park: Tropical Ecological And Cultural Restoration (San José, Costa Rica: UNED, 1988).

Jones Vargas, Luis, Informe de práctica para obtener el grado de Bachiller en Ciencias Agrícolas (Escuela Nacional de Agricultura, Costa Rica, 1942).

McNeill, John, The Historiography of Environmental History (Inglaterra: The Oxford History of Historical Writing, V. 5: Historical Writing Since 1945, 2011).

"México está que arde", La Nación (Costa Rica), 21 de mayo de 1998, 21A.

Montero Sánchez, Esteban "Climatología del período 1997-2015 y su relación con los incendios forestales en un sector del Pacífico Norte" (Informe de investigación, Universidad Nacional: Heredia, 2017).

Mora, Jorge, "La distribución de la tierra y los asentamientos humanos en Costa Rica", en: Centroamérica y los problemas del desarrollo en el campo (Santiago de Chile, Chile: FAO, 1990), 61-107.

Niele, Frank, Energy: Engine of Evolution (Amsterdam: Elsevier, Shell Global Solutions, 2005).

León Arguedas, Jorge, Botánica de los cultivos tropicales (San José, Costa Rica: IICA, 2000).

León, Jorge, Historia Económica de Costa Rica en el siglo XX. Tomo II: La economía rural (San José, Costa Rica: IICE-CIHAC, Universidad de Costa Rica, 2012).

León, Jorge et al, Desarrollo tecnológico en la ganadería de carne (San José, Costa Rica: Consejo Nacional de Investigaciones Científicas y Tecnológicas, 1982).

López López, Maximiliano, "Conservación y dinámica territorial en Costa Rica, de 1950 al presente", en: Raúl Fonseca et al., Cruce de caminos. Lecturas disciplinarias del territorio (FLACSO: San José, Costa Rica, 2020), 43-68.

Organización Meteorológica Mundial, Declaración de la OMM sobre el estado del clima mundial en 2015 (Suiza, 2016).

Padilla, Sixto Alberto, "El célebre pasto brasileño Androp gón Rufus (jaragua)", Boletín de Fomento (Costa Rica) 9 (Octubre de 1911): 660-669.

Parsons, James J., "Spread of African Pasture Grasses to the American Tropics", Journal of Range Management (1972): 12-17.

Parsons, James J., "Forest to Pasture: Development or Destruction?" Revista de Biología Tropical (Costa Rica) 24 (1976): 121-138. 
Pasos, Rubén et al, Incendios forestales y agrícolas en Centroamérica. Balance de 1998 (El Salvador: Comisión Centroamericana de Ambiente y Desarrollo-Consejo Centroamericano de Bosques y Áreas Protegidas, 1998).

Pausas, Juli, "Evolutionary fire ecology: lessons learned from pines". Trends in Plant Science 20 (5) (2015): 318-324.

Pausas, Juli, Incendios forestales: ¿desastre o biodiversidad? (Nicoya, Costa Rica: Conferencia presentada en la Sede Regional Chorotega-Universidad Nacional, 8 de mayo de 2013).

Pausas, Juli, Incendios forestales. Una visión desde la Ecología (Madrid: CSIC-Catarata, 2012).

Pérez, Samuel; Protti, Fernando, Comportamiento del sector forestal durante el período 1950-1977 (San José, Costa Rica: Oficina de Planificación Sectorial Agropecuaria, 1978).

Picado, Wilson; Botella, Elisa, "Tenencia de la tierra y cambio territorial en Costa Rica (1950-2014), en: Raúl Fonseca et al., Cruce de caminos. Lecturas disciplinarias del territorio (FLACSO: San José, Costa Rica, 2020), 15-41.

Picado Umaña, Wilson, "Las buenas semillas. Plantas, capital genético y Revolución Verde en Costa Rica". Historia Ambiental Latinoamericana y Caribeña (HALAC). Revista De La Solcha, 2 (2) (2013): 308-337.

Pittier, Henri, Plantas usuales de Costa Rica (San José, Costa Rica: Editorial Costa Rica, 1978).

Porras, Anabelle; Villarreal, Beatriz, Deforestación en Costa Rica. Implicaciones sociales, económicas y legales (San José, Costa Rica: Editorial Costa Rica, 1993).

Programa de Desarrollo Sostenible en Zonas de Frontera Agrícola de Centroamérica, Atlas Centroamericano de Incendios (Panamá, 1998).

Pyne, Stephen J., Fire. A Brief History (University of Washington Press, 2001).

Pyne, Stephen J., World Fire. The Culture of Fire on Earth (University of Washington Press, 1997).

Koonce, Andrea L.; González-Cabán, Armando, "Social and Ecological Aspects of Fire in Central America", en: Goldammer J.G. (eds), Fire in the Tropical Biota. Ecological Studies (Analysis and Synthesis), 84 (1990), 135-158.

Saborío López, Rocío, Diagnóstico sobre el comportamiento de la actividad ganadera. Período 1974-1984 (San José, Costa Rica: SEPSA-IICA, 1985).

Schindler, Ludwig et al., Incendios Forestales en Guatemala, Honduras y Nicaragua. Análisis de la situación presente y acciones a seguir (Alemania: Agencia Alemana de Cooperación Técnica, 2002). 
Sin autor, "El rey de los forrajes: el calinguero", La Escuela de Agricultura (Costa Rica) 2, N. 3 (Marzo de 1930): 64-65.

SINAC-Ministerio de Ambiente y Energía, Estrategia Nacional de manejo del Fuego, 2006-2010 (San José, Costa Rica: SINAC-Ministerio de Ambiente y Energía, 2005).

Ramírez, Alonso; Maltodano, Tirso, Desarrollo socioeconómico y el ambiente natural de Costa Rica. Situación actual y perspectivas (San José, Costa Rica: Fundación Neotrópica, 1988).

Rodríguez Solera, Carlos, "Estructura agraria de Guanacaste y políticas estatales en el Distrito de Riego Arenal-Tempisque" (Tesis de Licenciatura en Sociología, Universidad de Costa Rica, 1988).

Rodríguez, Silvia; Vargas, Emilio, El recurso forestal en Costa Rica. Políticas públicas y sociedad (Heredia, Costa Rica: Editorial de la Universidad Nacional, 1988).

Rowell, Andy; Moore, Peter, Global Review of Forest Fires (Suiza: WWF-IUCN, 1999).

Stephen J. Pyne, Fire. A Brief History (University of Washington Press, 2001).

Tapia Arenas, Claudia, "Análisis del cambio de cobertura forestal 2005-2015 en Guanacaste, Costa Rica" (Tesis de Licenciatura en Ingeniería Forestal, Instituto Tecnológico de Costa Rica, 2016).

Vargas, Gilbert, Sabana arbustiva del Parque Nacional Santa Rosa, 1928-2004 (San José, Costa Rica: CEMEDE-Universidad Nacional, 2005).

Vargas Sanabria, Daniela; Campos Vargas, Carlos, "Modelo de vulnerabilidad ante incendios forestales para el Área de Conservación Guanacaste, Costa Rica". Cuadernos de Investigación UNED (Costa Rica), V. 10 (2) (Diciembre de 2018): 435-446.

Villarreal, Beatriz, El precarismo rural en Costa Rica, 1960-1980 (Tesis de Maestría en Sociología, Universidad de Costa Rica, 1981). 


\title{
Incendiarism and Pyroculture in Costa Rica's Tropical Dry Forest. Fire History as Applied History
}

\begin{abstract}
This article analyzes the evolution of forest fires in Costa Rica from Applied History perspective. The article argues that agrarian structure shaped fire regimes in Costa Rica during the 20th century. Using the tools of Fire History and Fire Ecology, the paper identifies the historical processes implicated in fire regime formation in Costa Rica. The study is based on a review of primary and secondary sources, as well as maps and statistical data.
\end{abstract}

Keywords: Fire History; Forest Fires; Tropical Dry Forest; Applied History; Costa Rica.

Recibido: $11 / 02 / 2021$

Aprobado: 21/07/2021 